\title{
How do Executives Exercise Stock Options?*
}

\author{
Daniel Klein ${ }^{\dagger} \quad$ Ernst Maug $^{\ddagger}$
}

August 28, 2008

\begin{abstract}
We analyze a large data set of stock option exercises for a large data set of almost 200,000 option packages for more than 16,000 US top executives and analyze their motivations for the early exercise of their stock options. We estimate a hazard model to identify the main variables that influence executives' timing decisions and find that behavioral factors (e.g., trends in past stock prices), institutional factors (vesting dates, grant dates, blackout periods) and inside information strongly influence the timing of stock option exercises. By contrast, we find little support for the influence of variables proposed by utility-based models.
\end{abstract}

Keywords: Stock options, exercises, executive compensation

JEL classifications: G30, M52

\footnotetext{
*We are grateful to the collaborative research centers SFB 649 on "Economic Risk" in Berlin and the SFB 504 "Rationality Concepts, Decision Making and Economic Modeling" for financial support.

†University of Mannheim, D-68131 Mannheim, Germany. Email: klein@bwl.uni-mannheim.de, Tel: +49621 1811974.

${ }^{\ddagger}$ Corresponding author. University of Mannheim, D-68131 Mannheim, Germany. Email: maug@bwl.unimannheim.de, Tel: +49621 1811952 .
} 


\section{Introduction}

Stock option exercise behavior by top executives as well as non-executive employees has been widely studied in the literature, empirically and theoretically. However, there seems to be no consensus on the main drivers that influence stock option exercise behavior. For well diversified investors, it is optimal to hold American-style options to maturity unless they wish to capture significant dividend payouts. However, most executive stock options are exercised well before maturity, even if the stock does not pay dividends. A more recent literature argues that executives exercise their stock options too late compared to what rational undiversified investors would do and associates this discrepancy with behavioral biases. For example, Malmendier and Tate $(2005 \mathrm{a}, \mathrm{b})$ use the voluntary delay of stock option exercises as a measure of CEO overconfidence and validate this by comparing it to other measures.

The objective of this paper is to investigate alternative theories that have been developed to explain the timing of stock option exercises. We can distinguish four categories of explanations that have been advanced in the literature. The first strand of the literature argues that executives exercise their options before maturity in order to sell the shares and to better diversify their portfolios. ${ }^{1}$ Managers then have to trade off the benefits from diversification against the cost of giving up the time value of the option. A second strand of the literature shows that stock option exercise decisions are influenced by a range of behavioral factors. For example, individuals seem to exercise their stock options earlier if their company's stock trades above the maximum of recent stock price, and later when the stock falls below a recent minimum, which suggests that individuals compare stock prices to a reference stock prices. ${ }^{2}$ A third line of analysis shows that executives seem to anticipate future stock price developments and time their option exercises accordingly (Carpenter and Remmers, 2001). Finally, executives may exercise stock options because they are subject to exogenous shocks, for example when they need to finance major consumption items or when they leave the firm and would otherwise forfeit their options. ${ }^{3}$ All these explanations are not mutually exclusive and it is conceivable that one or even all four of these explanations contribute to the explanation of stock option exercise behavior. This paper evaluates the explanatory power of these theoretical approaches.

\footnotetext{
${ }^{1}$ The first paper to develop a formal model that incorporates this argument is Huddart (1994). Later papers followed up on this analysis, but extended the model to incorporate motives other than diversification benefits, such as liquidity shocks (Carpenter, 1998).

${ }^{2}$ An early paper is Heath, Huddart, and Lang (1999), see also Sautner and Weber (2006, 2008).

${ }^{3}$ Liquidity shocks are modeled in reduced form in Jennergren and Näslund (1993). Carpenter (1998) incorporates exogenous shocks into a utility-based model and finds that a model based on exogenous liquidity shocks performs better than a model based on utility-based arguments. However, Bettis, Bizjak, and Lemmon (2005) find that for a different and much larger sample the utility-based argument has additional explanatory power relative to a model based entirely on exogenous shocks.
} 
The methodological innovation of this paper is the use of hazard analysis, where the dependent variable is the conditional probability that a particular option is exercised, given that it has not been exercised so far. ${ }^{4}$ Two approaches have been used in the literature on stock option exercises. One group of studies uses a binomial approach and models stock option exercise behavior. The model is then calibrated to the median parameters of an appropriately constructed sample. ${ }^{5}$ The authors of these studies then compare the predictions of their models with respect to salient parameters (e.g., the stock price at exercise, the remaining maturity at exercise) with those observed in the data. An alternative and more empirical approach estimates a regression model to predict stock option exercises. ${ }^{6}$ Hazard analysis offers three advantages compared to these approaches. First, hazard analysis incorporates the fact that our data are censored because we cannot observe many option packages until maturity, either because the option is still alive (which is true for most options in our sample), or because the holder of the option left the firm; the filing records are then incomplete. Censored observations bias regression estimates, but can be treated appropriately with hazard analysis. Second, hazard analysis allows us to enter time-varying independent variables. Many variables we are interested in (e.g., functions of the stock price and stock returns, investor sentiment, the maturity of the option) are time-varying, so hazard analysis provides a natural tool for the analysis of these data. Third and finally, in addition to the variables suggested by the four groups of explanations discussed above, we can also control for a number of institutional features that vary over the lifetime of the option and that influence the timing of stock option exercises. This includes blackout periods, vesting periods, and seasonal effects.

We analyze a data set with 187,696 option packages of 15,683 executives at 2,326 firms based on the Insider Filing Data Feed (IFDF) of Thomson Financial that vest between 1995 and 2006. We find that a number of behavioral factors identified in the literature have first-order impact on stock option exercise decisions. In particular, executives respond to past stock returns in a way which suggests that they expect short-term trends to revert back to the mean, and there is somewhat weaker evidence that they extrapolate long-term trends in past stock prices. Salient

\footnotetext{
${ }^{4}$ Hazard analysis is also called survival analysis, duration analysis, transition analysis, our failure time analysis. The first paper to apply hazard analysis to option exercise decisions is Armstrong, Jagolinzer, and Larcker (2007). However, they apply this to a data set from many employees from a small number of firms, whereas we use a data set with the top managers from a large number of firms. Armstrong, Jagolinzer, and Larcker (2007) focus more on the implications for ESO valuation and less on the analysis of competing explanatory approaches to explain stock option exercises.

${ }^{5}$ The first binomial model is Huddart (1994). Carpenter (1998) and Bettis, Bizjak, and Lemmon (2005) calibrate binomial trees to match the moments of their samples by minimizing a loss function, which measures the distance between the predicted moments and the sample moments.

${ }^{6}$ Huddart and Lang (1996), Heath, Huddart, and Lang (1999), and Hallock and Olson (2006) fall into this category.
} 
statistics of past prices, like the maximum or the minimum price over the last year also have a strong influence, which is consistent with the explanation that past prices anchor perceptions and provide reference levels. We also find some support for the notion that managers time their option exercises because of inside information. By contrast, the variables suggested by utility theory do not work very well. Executives of firms whose stock is easier to hedge with the stock market index (and who, accordingly, are faced with less risk from the option overall) exercise their options earlier and some proxies of executives' wealth predict earlier exercises. These findings contradict the predictions of utility theory and do therefore not support the notion that executives exercise their stock options early in order to diversify their portfolios. Finally, we cannot analyze the theory that option exercises are determined by consumption needs and similar exogenous events because we cannot relate these to observable variables.

The next Section 2 describes the construction of our data set. Section 3 provides more details on the methodology and develops the hypotheses and the corresponding variable definitions in more detail. Section 4 contains the main results of the paper. Section 5 provides some robustness checks and Section 6 concludes.

\section{Data sources}

Our main data source is the Insider Filing Data Feed (IFDF) provided by Thomson Financial, which is based on the following information executives (insiders) have to file with the SEC: Form 3 ("Initial Statement of Beneficial Ownership of Securities"), Form 4 ("Statement of Changes of Beneficial Ownership of Securities"), and Form 5 ("Annual Statement of Beneficial Ownership of Securities") . Under Section 16 of the Securities Exchange Act of 1934 insiders in this sense are mainly direct and indirect beneficial owners of more than ten percent of any class of equity securities and any director and any officer of the issuer of such securities (Rule 16a-2). ${ }^{7}$ Insiders have to file transactions in derivative securities as well as in non-derivative securities, such as stock. These filings contain the numbers of securities transacted or held, transaction dates, expiration dates, strike prices, and vesting dates. The filings contain a verbal description of the respective vesting scheme instead of a date if vesting depends on other aspects than the date. However, IFDF does not contain verbal descriptions of vesting schemes. In this case the vesting date is missing.

\footnotetext{
${ }^{7}$ Rule 16a-1(f) defines "officer" to include the president, principal financial officer, principal accounting officer, any vice-president of the issuer in charge of a principal business unit, division or function (such as sales, administration, or finance), any other officer who performs a policy-making function, or any other person who performs similar policy-making functions for the company.
} 
IFDF contains filings of insiders' transactions in their companies' securities as well as holding records for stock and for derivative securities. Transactions included are, among others, purchases and grants of stock and options, sales, exercises, deliveries of withholding securities in order to pay an option's exercise price or the associated tax liability, the expiration or cancellations of derivatives, gifts of securities, dispositions to the issuer (e.g., forfeiture due to failure to meet performance targets, reloads), and transactions in equity swaps. ${ }^{8}$ For derivative securities, IFDF has different transaction codes for executive stock options (ESOs) and for market traded options.

We obtain the database for 2007. We extract all option packages that have at least one record with an ESO transaction code (grant, ESO exercise, delivery of stock to the issuer to pay for the exercise price) and non-missing entries in the identifying variables person ID, CUSIP of the underlying security, strike price, vesting date, and expiration date. For our analysis we remove all observations with incomplete or missing information about the vesting scheme. We retain only grants that vest between January 1, 1995 and December 31, 2006. In total, we obtain 1,534,713 option packages that account for 204,304 exercises by 124,766 insiders. The steps of the construction of the sample are summarized in Table 1.

\section{[Insert Table 1 about here.]}

We match the IFDF data to the 2007 version of ExecuComp to obtain additional information about the executives themselves. ${ }^{9}$ From ExecuComp we obtain the beginning and the end of employment by the company, the fiscal year end, and annual data on total compensation, the sum of base salary and bonus, the Black-Scholes value of options granted, and the value of restricted stock granted. We lose 1,264,340 option packages because we cannot match them to ExecuComp, mostly because ExecuComp covers larger firms and only the top 5 managers, whereas IFDF also covers smaller firms and insiders other than the top 5 executives. Missing observations in dollar denominated variables are set to zero.

We match this data with stock price data from Datastream. We lose another 37,343 options

\footnotetext{
"Withholding securities" is IFDF's terminology for a transaction where insiders can pay an option's strike price at exercise with the redeemed stock. IFDF separates this transaction: In the first transaction insiders receive all underlying shares, in the second transaction they give back some of these withheld shares to pay for the strike price. Bettis, Bizjak and Lemmon (2001) analyzed the use of zero cost collars and equity swaps by corporate insiders. From January 1996 to December 1998 they identified 87 collar transactions and two equity swap transaction and found that insiders reduced their effective ownership positions by such transactions on average by $25 \%$.

${ }^{9}$ We can match by person names and firms' CUSIPs. We match by first name, middle name, last name, and name affix ("Jr.", "Sr.", etc.). Sometimes one database contains the affix, whereas the other database does not. In such cases, we match by first name, middle name, and last name. If the middle name is also not available in one database, then we match by first name and last name only.
} 
because we cannot match observations to Datastream or because there is no stock price information on Datastream for the relevant period. Finally, we are only interested in options that are potentially exercisable. We therefore omit all options (45,334 in total) that are out of the money for the entire period from the vesting date to maturity. Executives sometimes exercise only a fraction of the option package. We therefore have to decide which of these exercise decisions to include. We are only interested in exercises that are economically significant and therefore only count those exercise decisions where at least $25 \%$ of the option package initially granted is exercised. Our final sample covers 187,696 option packages from 15,683 executives and 2,326 firms. For these options IFDF records 32,295 exercises.

We obtain annual dividend yields from Datastream. For firms-years with missing dividend information we set the dividend yield to zero. Additionally, we get dates of earnings announcements, dividend payments, and accounting data from WorldScope. The later hazard analysis will be based on weekly data. Thus, multiple exercises within one week will be aggregated into one single exercise decision.

[Insert Table 2 about here.]

The subjects of our analysis are option packages. Table 2 provides descriptive statistics for option packages at the vesting date for those options that are in the money for at least one week during the period between the vesting date and the maturity date. Executive stock options are American options, hence we follow Heath, Huddart, and Lang (1999) and calculate option values using the model of Barone-Adesi and Whaley (1987), which accounts for the early exercise premium for American options when the underlying stock pays dividends. We refer to these values as BAW-values from here on. For non-dividend paying stocks the BAW-values coincide with the Black/Scholes values. ${ }^{10}$ We further report the time to maturity at the vesting date, the moneyness, the volatility based on returns for the past 52 weeks, the dividend yields at the end of the last calendar year, and the interest rate. For the interest rate we use zero coupon yields with maturities of $1,2,3,5$, and 10 years and use the bond with a maturity that is closest to the maturity of the respective option. The value of option packages at the vesting date is $\$ 0.87$ million on average (median: $\$ 0.09$ million). Of the 187,696 option packages in our sample, 144,314 or $77 \%$ are in the money at the vesting date with an average stock price to strike price ratio of 7.48 (median: 1.29). The dividend yield is on average $0.79 \%$ (median:

\footnotetext{
${ }^{10} \mathrm{~A}$ more appropriate model for risk-averse managers is probably Detemple and Sundaresan (1999). However, their model requires the knowledge not only of managers' wealth, but also of the liquid portion of their wealth as well as assumptions about trading restrictions. We can therefore not implement their model.
} 
0.00\%). Hence, the price difference between American and European options plays a role for less than half of the option packages in our sample.

[Insert Table 3 about here.]

Table 3 reports descriptive statistics on stock option exercise decisions. We observe early exercises of some or all of the options for 29,442 option packages (16\% of the sample). There are on average 1.10 exercises per option package for those packages where some options are exercised early. On average, $83 \%$ of an option package is exercised if at least some options are exercised early. Hence, multiple exercises per option package exist, but they play a minor role in our sample. The median option is either fully exercised or fully held. If managers would minimize the costs from giving up the time value of the option, then they should always exercise the option with the highest ratio of the BAW-value to the inner value first, and they should exercise the options with the lowest ratio of the BAW-value to the inner value last. We see that in $36 \%$ of all cases managers exercise the option package with the minimum loss in time value. However, in $15 \%$ they exercise the option with the largest loss in time value. Finally, we ask to what extent the exercise boundary specified by the Barone-Adesi and Whaley (1987)-model is relevant for stock option exercise decisions. Only $18 \%$ of all exercises of options of dividend paying stock occur above this exercise threshold. This suggests that most of the exercise activity for ESOs is not related to dividends in the way specified by the BAW-model.

For the hazard analysis we use weekly data and exclude all weeks where an option package is out of the money. ${ }^{11}$ We only include options where the vesting date is available, so the standard left censoring problem considered in hazard analysis (options where the beginning of their relevant lifetime cannot be observed) does not exist for our data set. However, for $14 \%$ of all option packages in our sample we do not observe the grant date and there may be option packages that do not enter the database because their grant is not recorded on IFDF and they are not exercised early. We keep options without grant information in the data set and define the number of options granted as the number of options held at the first available transaction record or holdings record. For these options we potentially underestimate the total number of options granted and therefore overestimate the fraction that is exercised. If the number of options exercised exceeds the number of options granted we redefine the number of options granted as the total number of options exercised. Option packages without a grant record account for $87 \%$ of the exercises in our sample and we retain these observations, because

\footnotetext{
${ }^{11}$ Exercise of out-of-the-money call options is possible but irrational. For an analysis of irrational exercise behavior for exchange traded options see Poteshman and Serbin (2001).
} 
otherwise a large number of observed exercises would be lost. Grant dates tend to be missing for those option packages that were granted earlier, presumably because the coverage of the database was then less complete. For grants after 2000 the grant date is usually available. Since the options granted after 2000 have mostly not yet expired we observe fewer exercises for these options.

\section{[Insert Table 4 about here.]}

Right censoring is present in our analysis whenever we have no record of the exercise of an option. Since multiple exercises per option package are possible, an option package may be right censored even if a fraction of it was exercised early. We are interested in early exercises only because they involve an economic decision by the manager. Exercises at maturity are outside the scope of our analysis because they result from the decision not to exercise earlier and are therefore covered indirectly by the analysis of early exercises. Hence, from the point of view of our analysis all options that are not exercised until one week before they expire are right censored.

Right censoring occurs also because insiders leave the firm. Usually insiders have to exercise their ESOs within a certain period of time after they left the firm, otherwise their ESOs forfeit. However, the exact regulations are firm-specific and we do not have data on these. ${ }^{12}$ We therefore take the date when an executive leaves the firm (which we obtain from ExecuComp) as the censoring date. All exercises after this data, some but not all of which are recorded on IFDF, are therefore not included in our data set. Finally, all options that are still alive at the end of January 2007 are right censored because the coverage from our IFDF version ends on that date.

Table 4 shows the relative importance of right censoring reasons for the option packages in our sample. The table also shows if option packages are in the money (ITM) or out of the money at the censoring date. If some portion of an option package is disposed of early (through exercises or gifts) while the remaining part is censored, we report the option package in the table as censored only if the larger part is censored. The major reason for right censoring (71.9\% of the sample) is that the database records only exercises until January 2007. From the remaining $28.1 \%$, only about one quarter $(7.7 \%)$ of the options expire.

[Insert Table 5 about here.]

\footnotetext{
${ }^{12}$ Dahiya and Yermack (2007) have a detailed discussion of the rules for option forfeiture in these cases.
} 
Table 5 presents key financial statistics and compares the firms retained in our final sample (Panel A) with the firms on IFDF (Panel B). For each firm we first average the observations from 1996 to 2006 for all years where at least one option package exists and where we have data and then calculate the summary statistics reported in the table. The main observation from Table 5 is that our sample covers mainly large firms, whereas IFDF also covers smaller firms. The reason is our match with ExecuComp, which covers mainly the S\&P1500 companies. As a result, the median firm in the sample is larger than the median IFDF firm by a factor of about 10 in terms of market capitalization, total assets, and sales. Also the number of employees with option grants is higher in our sample than is the IFDF raw data.

\section{Methodology and hypotheses}

\subsection{Methodology}

We analyze stock option exercise patterns by CEOs and other insiders by using hazard analysis. ${ }^{13}$ To fix ideas, denote by $f\left(t, x_{t}\right)$ the probability density function for the event that the insider exercises her option package at time $t$, where the variables relevant for the decision (characteristics of the option package, the firm, the market environment, and the insider) are summarized in a vector of (potentially time-varying) variables $x_{t}$. Let $F\left(t, x_{t}\right)$ be the cumulative density function associated with $f$. Then the hazard rate $h\left(t, x_{t}\right)=f\left(t, x_{t}\right) /\left(1-F\left(t, x_{t}\right)\right)$ is defined as the conditional instantaneous probability that the insider exercises her stock options at time $t$ if she has not exercised them yet. ${ }^{14}$

In principle, we could estimate the conditional density $f$ directly, for example by way of a logit or probit model and then infer unconditional probabilities. ${ }^{15}$ Apart from the methodological difficulties of actually doing so, direct estimation of the hazard rate $h\left(t, x_{t}\right)$ offers three major advantages, which we outline in the introduction. First, hazard analysis allows us to include time-varying state variables (covariates) $x_{t}$. For example, we will be interested in the likelihood that the insider exercises her options conditional on the stock price development prior to time $t$, conditional on the stock price and the value of her portfolio at time $t$, and conditional

\footnotetext{
${ }^{13}$ The discussion in this section is based on Kiefer (1988), Lancaster (1990), and chapter 17 of Cameron and Trivedi (2005).

${ }^{14}$ This is only a conceptual discussion to fix ideas. Our definition of Exercise implies that the same option package can be exercised more than once (multiple spell analysis). Our econometric analysis accounts for this fact. We keep options in the analysis as long as at least an economically significant fraction of the initially granted number of options $(25 \%)$ is left.

${ }^{15}$ In his survey, Kiefer (1988) insists that "the hazard function approach does not identify new parameters" (p. 649) because parameterizing the problem in terms of conditional or unconditional probabilities is equivalent.
} 
on time-dependent events like blackout periods or the arrival of new option grants. These timevarying covariates can be naturally included in hazard analysis. Second, hazard analysis can easily deal with censoring of the data. We have right censoring but no left censoring in our sample (see the discussion in Section 2, in particular Table 4 above). Neglecting such censoring therefore biases the estimate of the hazard rate upwards because some exercise decisions are not observed. Third, this analysis allows us to control for time-varying institutional factors.

We proceed by using the Weibull-model, a standard parametric hazard model used in a range of economic applications, which is specified as follows:

$$
h\left(t, x_{t}\right)=p t^{p-1} \exp \left\{\beta_{0}+x_{t}^{\prime} \beta\right\},
$$

where $x_{t}$ is the time-varying vector of covariates, $p$ and $\beta_{0}$ are scalars, and $\beta$ is a vector of coefficients. Conventionally, the expression for $h\left(t, x_{t}\right)$ is factored into two components. The first is $p t^{p-1} \exp \left\{\beta_{0}\right\}$ and referred to as the baseline hazard, whereas the second $\exp \left\{x_{t}^{\prime} \beta\right\}$ is the relative hazard. We express all non-dummy covariates in mean-deviations, scaled by the standard deviation. So, the relative hazard equals 1 for an option grant where all non-dummy variables are at their means and all dummy variables equal zero. For such an option grant the hazard rate is $h(t, \bar{x})=p t^{p-1} \exp \left\{\beta_{0}\right\}$, so the baseline hazard can be interpreted as the conditional density of exercising an option if all non-dummy covariates are at their means and all dummy variables are zero. We use clustered robust standard errors at the level of the firm since many variables (stock price developments, alphas, CARs, volatility, correlation, weeks of earnings or dividends, etc.) are identical for all individuals and option grants of the same firm.

An important special case considered in the literature is the exponential hazard function, which is obtained from (1) by setting $p=1$, so the baseline hazard rate becomes $\exp \left\{\beta_{0}\right\}$ and therefore independent of time. The Weibull model (1) used here is more flexible and allows for the case where $p<1(p>1)$, then the hazard rate is decreasing (increasing). The conditional probability for an option to be exercised over a period of length $\Delta t$ can be approximated by $h\left(t, x_{t}\right) \Delta t$ and decreasing hazard rate means that this probability is decreasing over time, holding everything else constant. ${ }^{16}$ An attractive feature of the Weibull model is this separation of the direct impact of time, which is captured in the baseline hazard rate, from the impact of the time-varying covariates $x_{t}$. Hazard rate models are defined in continuous time, so we have to use a discrete-time approximation. We follow Heath, Huddart, and Lang (1999) and

\footnotetext{
${ }^{16}$ Kiefer (1988) highlights the possibility of obtaining constant hazard rates as a special case of the Weibull model as an additional advantage of this model over the lognormal or the log-logistic models or over the direct estimation of unconditional probabilities.
} 
use weekly observations.

\subsection{Variable definitions and hypothesis development}

In this Section we introduce the covariates included in our hazard rate model. We group variables by the different hypotheses that have been advanced in the literature as explanations of early stock option exercises by executives. Table 6 provides a detailed overview of all variables and their definitions used in this paper.

\section{[Insert Table 6 about here.]}

Dependent variable: Exercise. The unit of investigation for our study is an option grant or package. The dependent variable in all our regressions is the dummy variable Exercise $_{t}$, which assumes a value of one if the options in the grant are exercised at time $t$ and zero otherwise. However, often managers do not exercise the options from the same grant all at the same time. We therefore define Exercise $_{t}$ as the event where the manager exercises at least $25 \%$ of the options originally granted in one option grant. Hence, exercises of less than $25 \%$ of grant $j$ at time $t$ imply that Exercise $_{j t}=0$, and grants where less than $25 \%$ of the options granted initially are left are dropped from the analysis. Sometimes managers receive options with different conditions (strike prices, vesting periods) at the same date and we treat these as separate grants, so all options in one grant have the same strike price and are subject to the same vesting conditions. The $25 \%$-threshold is somewhat arbitrary, and we also provide results in Section 5 where the threshold value is set to $10 \%$ and where it is set to $50 \%$, respectively.

Behavioral explanations. To the best of our knowledge, Heath, Huddart, and Lang (1999) were the first to explicitly introduce behavioral factors into the analysis of stock option exercise patterns. They show that individuals' exercise decisions respond to past stock prices, which cannot be rationalized by explanations based on utility theory. We follow Heath, Huddart, and Lang (1999) and group behavioral explanations into two sets: Explanations based on beliefs and explanations based on preferences. Individuals seem to form beliefs based on the rule that short-term trends revert back to the mean, whereas long-term trends continue. ${ }^{17}$ If managers believe that a recent upward trend in their company's stock reverts to the mean, then they believe that their stock is currently overvalued, so it becomes optimal for them to exercise the option and sell the overvalued stock now, providing the time value is not too large. By contrast, if managers believe a trend to continue, then exercising now is not optimal.

\footnotetext{
${ }^{17}$ Kahneman and Tversky (1973), Tversky and Kahneman (1971).
} 
We expect individuals to pay attention to whether their stock outperforms or underperforms the market. We therefore regress the stock of the company on the S\&P 500 stock market index and compute the intercept $\alpha=\bar{r}_{\text {Stock }}-\beta \bar{r}_{\text {Market }}$ from this regression as a measure of outperformance relative to the market index. The psychological literature does not specify when a trend has to be regarded as short (and therefore mean-reverting) and when it has to be regarded as long. We therefore use three definitions of $\alpha$, Alpha26, Alpha52, and Alpha156, which are the $\alpha$-estimates over 26 weeks, 52 weeks, and 156 weeks, respectively.

Heath, Huddart, and Lang (1999) refer to prospect theory (Kahneman and Tversky, 1979) to motivate the notion that individuals value their options by comparing the current stock price to a reference price. If the stock trades above this reference price, then individuals are risk-averse and evaluate the costs and benefits of option exercises like a risk-averse investor. However, if the stock trades significantly below the reference price, then individuals become risk-seeking. A loss-averse manager whose company's stock trades below her reference price is therefore unlikely to exercise her options. ${ }^{18}$ The psychological literature offers little guidance on how individuals set their reference prices and we follow Heath, Huddart, and Lang (1999) and include MaxPrice, a dummy variable which is one if the stock price in week $t$ is above its maximum over the preceding 52 weeks. Similarly, we define MinPrice to equal one if the stock trades below its 52-week minimum. We expect that individuals exercise their options more frequently if the stock trades above their reference point and less frequently if it trades below their reference point. Consequently, the predicted coefficient on MaxPrice is positive and the predicted coefficient on MinPrice is negative.

Many authors have documented the impact of investor sentiment on asset prices. ${ }^{19}$ We expect that stock option exercise decisions also respond to investor sentiment. If managers behave like small retail investors, then we expect that they invest more in risky stocks if investor sentiment is bullish and less if investor sentiment is bearish. Accordingly, we expect that managers who are subject to investor sentiment exercise their options later if investor sentiment is high. However, if managers are more rational, they may recognize that prices are temporarily bid up by bullish noise traders (or depressed in the opposite case) and then exercise their options earlier. For the purpose of our analysis we adopt the view of Lemmon and Portniaguina (2008) and Qiu and Welch (2006) and use a measure of consumer confidence as an indicator of investor sentiment. ${ }^{20}$ We use $C C I$ as an index of consumer confidence and

\footnotetext{
${ }^{18}$ Heath, Huddart, and Lang (1999) relate their argument about reference-dependence to the disposition effect. However, it is not clear to what extent loss-aversion can explain the disposition effect.

${ }^{19}$ For an early paper see Lee, Shleifer, and Thaler (1991).

${ }^{20}$ See Baker and Wurgler (2006) for a discussion of several other measures of investor sentiment.
} 
expect the coefficient on this index to be negative if managers behave like noise traders, and we expect it to be positive if they act like rational investors.

Utility theory. The starting point of utility theory is the observation that insiders exercise their stock options early because their investment in their own company's securities exposes them to firm-specific risk. Exercising their stock options early allows insiders to diversify their portfolio, in particular when they sell the stock they receive from exercising their options. Huddart (1994) develops a theoretical model along these lines, which analyzes the trade-off between the benefits from diversification and the costs of giving up the remaining time value of the option. In his model, the manager has power utility, so her absolute risk aversion decreases in her wealth.

A manager with constant relative risk aversion is more likely to exercise her stock options earlier if: (1) she is more risk averse, (2) if she is less wealthy, so that her absolute risk aversion is lower; (3) if a larger fraction of her wealth is invested in the firm's securities. If the manager is more risk averse, then she gives a higher weight to the costs of having an undiversified portfolio and therefore exercises earlier. Similarly, if she is less wealthy, her absolute risk aversion and her benefit from diversifying is lower, so she exercises later.

The effect of the stock's volatility on the decision to exercise early is ambiguous as there two effects here. Higher volatility makes the option more risky, so that a risk-averse manager would exercise early. However, volatility also increases the time value of the option. The first effect outweighs the second effect only if the manager is sufficiently risk-averse, so we cannot make an unqualified prediction here.

We cannot observe managers' wealth directly as this would require knowledge of each manager's non-firm related wealth. ${ }^{21}$ We therefore construct three variables based on the manager's compensation. FirmSecurities ${ }_{j t}$ is the value of all shares (restricted stock as reported in ExecuComp) and the entire option portfolio of the manager, with the exception of grant $j$, where grant $j$ refers to the current option package. ValueThisGrant ${ }_{j t}$ is the Barone-Adesi and Whaley (1987) value of all options in grant $j$ that have not been exercised until time $t$ and that were excluded from FirmSecurities F $_{\text {. }}$ From the point of view of utility theory there should be no difference between wealth invested in option grant $j$ and wealth invested in other securities, so we should expect the coefficients on FirmSecurities Fit $_{\text {and }}$ ValueThisGrant Th $_{\text {to }}$ to

\footnotetext{
${ }^{21}$ Becker (2006) has data on CEO wealth for Sweden, but this data is not available for the US. Dittmann and Maug (2007) approximate CEO wealth by assuming a reinvestment scheme based on the CEO's past income, but this requires knowledge of at least five years of past data, which is also not available for most managers in our sample.
} 


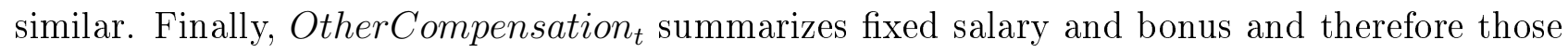
compensation components that do not depend on the stock price. We expect the coefficients on all components of wealth to be negative and the coefficient on OtherCompensation should be largest in absolute value since OtherCompensation adds less risk than the other proxies for wealth.

We measure the riskiness of the firm by two variables. Volatilityt is defined as the standard deviation of stock returns calculated over the 52 weeks preceding week $t$. Correlation Cis the coefficient of correlation between the firm's stock return and the return on the S\&P 500 . Correlation captures the idea that the manager can hedge the market-risk of the stock by trading in the stock market, whereas she cannot hedge the idiosyncratic risk of the firm. ${ }^{22}$ We expect that managers exercise options earlier if the idiosyncratic risk is higher, so the coefficient on Correlation should be positive. For the reasons mentioned above we cannot make an unambiguous prediction for the coefficient on volatility.

The model in Huddart (1994) develops an exercise boundary in terms of the ratio of the stock price to the strike price of the option, $S_{t} / K$. We define this variable as Moneyness and expect that it has a positive coefficient: if $S_{t} / K$ is above its critical value, then the manager should exercise the option, whereas she should not exercise if Moneyness is below its critical value. Heath, Huddart, and Lang (1999) argue that the exercise boundary defined in Huddart (1994) is a non-linear function of the maturity of the option. We therefore adopt the same approach as Huddart and Lang (1996) and also use the square of Moneyness, defined as Moneyness2.

Institutional variables and constraints. Managers' exercise decisions are subject to a range of institutional constraints. We introduce a number of variables here to capture these constraints. These variables cannot necessarily be related to any of the theoretical explanations of option exercise behavior we are interested in, but in the context of our approach it seems appropriate to include the relevant variables as controls.

First, and most obvious, is the vesting period itself, which prevents managers from exercising their options before the vesting date. Utility theory predicts that managers exercise their options immediately after the vesting date if the stock price on the vesting date exceeds a certain threshold. Similarly, the behavioral explanations may also imply that a manager would sell her options, for example, because she believes the stock price to drop or because the stock

\footnotetext{
${ }^{22}$ Cai and Vijh (2005) present a utility based ESO valuation model where the manager can invest in the risk-free money market account and two correlated risky assets: stock and market portfolio. They show that managers value options subjectively higher when the the correlation between returns of the stock and the returns of the market portfolio is high.
} 
price is sufficiently above her reference price. In either case, the vesting constraint is binding and we should expect that managers exercise a significant portion of their options immediately after the options vest. We include VestingWeek, a dummy variable which equals one in the week of and the week after the option vests and expect the coefficient on this variable to be positive.

Managers may also respond to the arrival of new option grants by exercising more of their existing options. This would always happen if managers have some target ownership of stock options, so that a new option grant increases their holdings above their target level. ${ }^{23}$ For example, ownership guidelines or more implicit components of managers' contracts may oblige them to hold a certain portion of their wealth in their companies' securities. From the point of view of utility theory, managers would exercise their existing options if they receive a new grant simply because new option grants increase the exposure of the manager to firm risk. We include GrantWeekBefore, a dummy variable which equals one in the week before the manager receives a new option grant, and GrantWeekAfter, a dummy variable which equals one in the week of and the week after a new option grant. We expect the coefficients on both variables to be positive.

Most firms restrict trading of insiders by imposing black-out periods where insiders are not allowed to trade. Bettis, Coles, and Lemmon (2000) show that $92 \%$ of the firms in their sample impose such trading restrictions and that these trading restrictions lead to a significant decline in trading activity and a narrowing of bid-ask spreads for the firm's stock. They show that a common window imposed for trading is 3-12 days after earnings announcements. Since most managers sell the shares they receive from option exercises immediately upon exercise, we expect that trading restrictions around earnings announcements also affect exercise patterns. We capture this with two variables, EarnAnnounceBefore, a dummy variable which equals one in the week before the earnings announcement, and EarnAnnounceAfter, a dummy variable which equals one in the week of until two weeks after earnings announcements. If stock option exercises respond to trading restrictions for the company's stock, then we expect the coefficient on EarnAnnounceBefore to be negative and the coefficient on EarnAnnounceAfter to be positive.

Managers may adjust their exercise strategies to their companies' dividend policies if their options are not dividend protected. ${ }^{24}$ They benefit by exercising the option as long as it still

\footnotetext{
${ }^{23}$ The results from Ofek and Yermack (2000) are consistent with the notion that senior managers have ownership targets with respect to their stock holdings, so that they build up their ownership if they are below this target.

${ }^{24}$ If dividend protection arises through adjustments in the strike price the strike price in IFDF is missing.
} 
trades cum dividend. We therefore included Dividend and DividendYield to capture this aspect. Dividend is a dummy variable which equals one in the week before and the week of a dividend payment. We also need to take into account that any investor would exercise the option before a dividend payment only if capturing the dividend is sufficiently important relative to giving up the time value of the option. The Barone-Adesi and Whaley (1987)-model (BAWmodel) specifies a boundary of the stock price, where exercising is optimal only if the stock price is above this boundary. We therefore define $B A W$ Bound as a dummy variable that equals one if the stock price is above the BAW-boundary and zero otherwise. DividendYield is the dividend yield at the end of the last calendar year and measures the size of the dividend captured through early exercise. We expect the coefficients on both, Dividend and DividendYield to be positive.

Asymmetric information. Employees of the companies in our sample may have private information and time their stock option exercises. Huddart and Lang (1996) find exercise patterns consistent with this notion. Interestingly, they cannot detect significant differences between senior managers and lower-level employees in their sample. However, managers who exercise their stock options in advance of the disclosure of bad news by the firm may be charged with insider trading. This is more likely to be the case for news disclosures that follow immediately after managers exercised their options compared to news that cannot be easily related to managers' exercise decisions. We therefore calculate the cumulative abnormal returns for the weeks following exercise decisions and include as variables in our regressions $C A R 2, C A R 13$, and $C A R 26$, the cumulative abnormal returns for, respectively, 2 weeks, 13 weeks, and 26 weeks after week $t$.

Other explanations and control variables. We include some additional variables that cannot be related to particular hypotheses. We include dummy variables Quarter2, Quarter3, and Quarter4 to capture potential seasonal effects in exercise patterns.

Exercise behavior may depend on the status of the manager in the hierarchy of the firm. However, without a detailed understanding of the internal organization of the firm and the assignment of labels to particular positions it is difficult to assign individual managers to layers in the corporate hierarchy in a way that is comparable across firms. Also, we match the IFDF data to ExecuComp and have therefore only data on the top five executives. We therefore distinguish only between the CEO and other managers. We expect that CEOs are more likely Hence, such options are dropped from our sample. 
to hold options for incentive reasons and to be subject to ownership guidelines compared to lower-level employees. Also, CEOs may be subject to the illusion from control and believe the stock price to rise and therefore their stock options to be undervalued. Any of these reasons would reduce their exercise rates compared to those of other managers. We therefore include a dummy that equals one for CEOs.

All managers will trade off the benefits from early exercise against the costs of losing the time value of the option. The foregone time value should therefore be included irrespective of whether the benefits are better described by rational, behavioral, or institutional factors. We include two variables to capture this. First, the variable InnerValue is defined as the inner value of the option (stock prices minus strike prices), divided by its Barone-Adesi and Whaley (1987)-value (BAW-value). For options where the time value is large, this ratio is significantly smaller than one, for options where the time value is negligible, the BAW-value is almost equal to the inner value and then InnerValue equals one. ${ }^{25}$ We expect that managers exercise options where the ratio of inner value to Black-Scholes value is large, so the coefficient on InnerValue should be positive. Second, we also include Maturity, which is the remaining maturity of the option. In addition, we also expect that whenever managers exercise their options at maturity, they will do so somewhat close to the maturity date. We define Maturity4WeeksBefore as a dummy variable, which equals one in the four weeks before the maturity of the option and zero otherwise. We expect that many managers exercise their options shortly before maturity, so the coefficient on this variable should be positive.

Several authors have suggested exogenous shocks as an additional explanation for the early exercise of stock options. However, we do not have any data on these exogenous shocks and we can therefore not test this theory. ${ }^{26}$

Table 7 provides summary statistics of all independent variables used in our regressions.

\section{[Insert Table 7 about here.]}

The mean of MaxPrice indicates that the stock price is above its 52 weeks maximum in $16 \%$ of all weeks. Conversely, the probability that the stock price is below its 52 weeks minimum is only $2.3 \%$. To some extent, this asymmetry arises because we include only weekly observations where options are in the money. The median option holder owns firm securities (other than

\footnotetext{
${ }^{25}$ Armstrong, Jagolinzer, and Larcker (2007) use the remaining time to maturity of the option to capture the inner value. Heath, Huddart, and Lang (1999) use the estimator of Barone-Adesi and Whaley (1987) for American options instead of Black-Scholes for approximating the value of the option. We expect that all three proxies for inner value will be highly correlated.

${ }^{26} \mathrm{Liu}$ and Yermack (2007) hand collect data on CEO's home purchases, which may represent the most important source of liquidity needs for CEOs. Their data cover only a very small part of our data set.
} 
the current option package) with a value of $\$ 8.89$ million and receives annual base salary and bonus of $\$ 545,000$ (not tabulated). $15 \%$ of our option packages are held by CEOs.

\section{Analysis}

We need to break up our sample into several parts because the estimation of the model is computationally infeasible for larger data sets. This also allows us to compare results across subsamples. We therefore group our observations randomly into 10 subsamples, where we assign all observations for the same option package to the same subsample. We summarize the estimation results in two tables.

[Insert Tables 8 and 9 about here.]

Table 8 reports the hazard rates that follow from our coefficient estimates for $\beta_{0}, \beta$, and $p$ from equation (1) separately for each subsample. We report relative hazard rates for individual variables as $h r_{i}=\exp \left\{\beta_{i}\right\}-1$ to ease interpretation. ${ }^{27}$ We express all variables other than dummy variables as deviations from their means, scaled by their standard deviations. Hence, if $\exp \left\{\beta_{i}\right\}-1$ equals 0.3 , then this implies that a one standard deviation increase in $x_{i}$ increases the probability of exercise in week $t$ by $30 \%$. For the dummy variables $\exp \left\{\beta_{i}\right\}-1$ is simply the change in the hazard rate if the dummy variable changes its value from zero to one. The reported $R^{2}$ represents the adjusted proportion of explained variation for proportional-hazards (PH) models for censored survival data (Royston, 2006).

Table 9 summarizes the results for all subsamples and shows the average hazard rate (averaged over all ten subsamples), the coefficient of variation of the hazard rate, defined as the standard deviation over all ten subsamples divided by the mean coefficient; an aggregated tstatistic, which divides the mean coefficient by the aggregate standard deviation, calculated as $\sqrt{\sum_{k=1}^{k=10} \sigma_{k}^{2}}$, where $k$ indicates the respective subsample; the number of positive coefficients, the number of negative coefficients, the number of coefficients that are significant at the $5 \%$-level and positive, and the number of coefficients that are significant at the $5 \%$-level and negative.

The estimates in Tables 8 to 9 refer to the baseline case where the dependent variable Exercise is defined to be one whenever at least $25 \%$ of an option grant are exercised. We perform robustness checks for different definitions of the dependent variable where this threshold is set to $10 \%$ and $50 \%$, respectively.

\footnotetext{
${ }^{27}$ Conventionally, the relative hazard are defined as $\exp \left\{\beta_{i}\right\}$, which then has the interpretation of a factor. Since $\beta_{i} \approx \exp \left\{\beta_{i}\right\}-1$ for sufficiently small $\beta_{i}$, our convention saves us from reporting separate tables for the coefficients.
} 
Behavioral factors of stock option exercises. Our results support the notion that managers believe in mean reversion. The coefficients on Alpha26 are all positive and significant at the 5\%-level and the aggregated t-statistic is 27 . The impact is also economically large. If the firm outperforms the benchmark by one standard deviation (1.9\% p.a., see Table 7$)$, then the likelihood of exercising the option increases on average by $34 \%$. Hence, managers exercise options more frequently if their company's stock has done well recently, which suggests that they exercise their options and sell the resulting stock because they expect the stock price to decline. The coefficients on Alpha52 are mostly positive but never significant, so mean reversals seem to be expected for stock price increases that last less than one year.

The coefficients on Alpha156 are consistently negative but not individually significant in most cases. The fact that 9 coefficients have the same sign and the aggregate t-statistic of -6.45 suggest that this is a consistent effect, albeit not a strong one: if Alpha156 increases by one standard deviation, then the likelihood of exercise falls by $4 \%$. This is consistent with the notion that managers believe that longer term trends will continue, whereas short-term trends will reverse. These results are in line with the findings of Heath, Huddart, and Lang (1999) with the notable difference that their definition of long-term trends refers to shorter horizons (within one year) than our definition.

The dummy variable MaxPrice is consistently significant with positive coefficients. On average, the likelihood that managers exercise their options increases by $65 \%$ if their company's stock trades above its 52-week maximum. The effect of MinPrice is also measurable, but weaker (individually significant in four cases, aggregate t-statistic of -5.37). If the stock trades below its 52-week minimum, then the probability of exercise decreases by $31 \%$. This supports the notion that managers remember salient stock prices like minima and maxima and use these to form reference points and tend to exercise their options if the stock trades above or below these reference points.

Finally, the coefficient on $C C I$, our measure of investor sentiment, is positive in all ten regressions and statistically significant in seven of them, with an aggregate t-statistic of 14.80 . A one-standard deviation increase in the consumer confidence index increases the probability of an early stock option exercise by $13 \%$. This effect is therefore economically significant and contradicts the notion that managers are influenced by investor sentiment in their exercise decisions. Rather, they seem to anticipate lower future returns if investor sentiment is high and noise traders inflate current prices. Then insiders exercise their stock options earlier.

Overall, we find strong support for the notion that managers expect the reversion of recent trends in their stock price and that they use salient past stock prices to establish a reference 
level. By contrast, the evidence for extrapolating long-term trends is weak and the corresponding effect small. Also, managers seem to believe that their stock price is inflated by investor sentiment.

Utility theory. The coefficient on Moneyness is negative in nine out of ten subsamples and statistically negative in two cases (the aggregate t-statistic is only -0.31 though). The effect of the square of Moneyness, Moneyness 2 is even weaker (aggregate t-statistic of 0.07). The evidence is therefore not strong here and does not support the implications of utility theory that there is an exercise boundary above which managers will exercise their options.

The implications regarding Correlation are more general and we expect a negative coefficient here because a higher correlation with the stock market index allows managers to hedge a larger proportion of the risk from their options, so that they should exercise later. However, the coefficient on Correlation is positive and statistically significant in all subsamples and implies that a one-standard deviation increase in Correlation increases the probability of exercise by 11\%. This finding is corroborated by the coefficient on Volatility, which is negative and statistically significant in all subsamples, so managers of riskier firms exercise their options later. Hence, if the need to diversify is present at all, it is sufficiently weak to be outweighed by the opposite effect that the options of riskier firms have a higher time value and should therefore be exercised later.

Finally, we turn to the proxies for wealth, FirmSecurities, ValueThisGrant, and OtherCompensation. If these variables measure wealth, then they should all have negative coefficients, with OtherCompensation having a larger coefficient in absolute value. Note that these implications hold only for specifications of utility theory that imply decreasing absolute risk aversion (like the standard CRRA models used in the ESO literature) and not for utility theory in general. Our findings are not consistent with the predictions of the CRRA-model. The coefficient on OtherCompensation is positive for all ten subsamples, and it is statistically significant in seven out of ten cases (average t-statistic is 31.81). The coefficients on FirmSecurities F $_{j}$ and ValueThisGrant are always negative as predicted, but mostly insignificant. The effects of all three variables are economically moderate and imply increases of $5 \%$ (for OtherCompensation), respectively, decreases of 5\% (for ValueThisGrant and FirmSecurities ${ }_{j}$ ).

Summarizing, none of the implications of utility theory is borne out by the data and we therefore conclude that utility theory has no explanatory power with respect to stock option exercise behavior. 
Institutional variables. Many options are exercised immediately after they vest. The hazard rate for VestingWeek shows that in the week of and the week after vesting, exercise rates are higher by $983 \%$. This is consistent with the notion that the vesting constraint is binding, either for diversification reasons or for behavioral reasons, so that managers exercise options immediately after they vest.

Quantitatively almost as important is the impact of GrantWeekAfter, a dummy which equals one in the week of and the week after the manager receives a new option grant. On average, the likelihood of exercising options in the week of or in the week after a new option grant is $410 \%$ higher than usual. This is consistent with the notion that new option grants increase managers' option holdings above their target level. By comparison, the impact of GrantWeekBefore is statistically insignificant in all subsamples. Overall, this evidence suggests that managers try to keep their option holdings at some target level and tend to exercise existing options when they are granted new options. Such a target level might be explained by utility theory. If the level before the arrival of a new grant represents a portfolio equilibrium, then the new grant increases the executive's exposure to firm-specific above its equilibrium level and triggers exercises of existing grants. Similarly, ownership guidelines may imply a target exposure to firm risk, so that new option grants can then be followed by exercises of existing grants.

Trading restrictions because of blackout periods seem to be important. The coefficients on EarnAnnounceBefore and EarnAnnounceAfter always have the predicted signs and are mostly statistically significant. In the week before earnings announcements, exercises are on average $63 \%$ below their normal rate (significant in 6 subsamples). In the week after earnings announcements, exercises are $82 \%$ above their usual level and this effect is statistically significant in all subsamples. Hence, managers seem to shift their exercise decisions from the period before earnings announcements to the period immediately after the announcement.

The coefficients on Dividend are mostly negative, which contradicts the notion that managers exercise options before dividend dates. However, this effect is significant in only one subsample. The coefficients on DividendYield are always insignificant but positive in eight out of ten subsamples (aggregate t-statistic is 4.44). The coefficient on BAWBound is positive or negative half of the time. Based on the notion that managers capture dividends on non-dividend protected options by exercising them before dividend payment dates, we expect the signs of all three variables to be positive and find no support for this prediction. Recall that dividend yields are typically low (see Table 2) and dividends may therefore not play a 
major role for our sample. ${ }^{28}$ Note that the BAW-boundary applies to a model with diversified investors who can trade the underlying assets and may therefore not be relevant for risk-averse executives. $^{29}$ We can effectively exclude the possibility that options are dividend protected because dividend protection is normally achieved through strike price adjustments. Then there is a footnote in the respective field in the original filings and a missing strike price in IFDF. We exclude derivatives with missing strike prices, so dividend protected options do not enter our data set.

Asymmetric information. If managers exercise later because they expect positive news to materialize, or if they exercise earlier because they expect negative news to materialize, then the coefficients on $C A R 2, C A R 13$, and $C A R 26$ should be negative. We find that the coefficients on either $C A R 13$ or $C A R 26$ are significant and negative as predicted for all subsamples except subsample 7 (only $C A R 26$ at the 10\%-level) and subsample 9. However, only one of the coefficients on $C A R 2$ is significant, although the coefficients are significant in the aggregate (t-statistic of -7.85). We interpret this as consistent evidence that timing considerations based on inside information play an important role in stock option exercise decisions. We conclude that managers have some inside knowledge that helps them to predict medium-term (one or two quarters) developments in the stock price, but they are more cautious in using information that will be disclosed over a period as short as two weeks.

Other variables. The coefficients on InnerValue are among the most significant in our analysis. The coefficients are always positive and significant at least at the 1\%-level. Hence, independently of whether behavioral reasons or diversification motives better explain exercise behavior, managers consistently take the cost of losing the time value of their options into account.

CEOs exercise their options later and CEOs are $8 \%$ less likely to exercise their options compared to the other top-5 managers. This may be because of behavioral factors (e.g., a delusion of control) or institutional contstraints (e.g., ownership guidelines) that induce CEOs to hold their options longer than other executives.

\footnotetext{
${ }^{28}$ The low significance for Dividend might come from the fact that we have dividend payment dates only for 16,815 option grants out of 79,839 grants where the underlying stock pays dividends.

${ }^{29}$ Detemple and Sundaresan (1999) develop a model for risk-averse investors and short-sales restrictions in the underlying asset. They show that the resulting exercise behavior can be described by a model where the stock pays an additional dividend, even if the actual stock does not pay any dividends at all. This may be conceived as the opportunity cost of not exercising the option.
} 


\section{$5 \quad$ Robustness checks}

We perform several robustness checks. First, as mentioned earlier, we redefine the dependent variable and use thresholds of $10 \%$, respectively, $50 \%$ to define the dependent variable. We report summary statistics analogous to Table 9 .

[Insert Tables 10 and 11 about here.]

Our results are stable with respect to alternative definitions of the dependent variable. It is particularly instructive to look at the number coefficients that are significant at the 5\%-level. These are practically identical for each variable and independent of the definition of the dependent variable. If the threshold for defining Exercise is higher, the effects of Alphas156 are somewhat stronger (2 versus 0 samples with significant coefficients). The

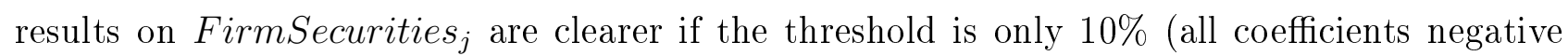
and significant at the 5\%-level), whereas significance basically vanishes for the higher threshold. The results for ValueThisGrant are most strongly affected by changes in Exercise. If Exercise is defined with a 10\%-threshold, then the coefficients on ValueThisGrant are all positive (significant in 2 cases), while they become negative if the threshold is $25 \%$ (significant in 3 cases) and 50\% (significant in all cases). Our interpretation is that executives are more likely to exercise larger grants in smaller fractions, whereas they will exercise smaller grants in larger fractions. Hence, a higher value of ValueThisGrant implies that the grant is larger and more likely to be broken up into smaller pieces (hence, the value for the 10\%-threshold is positive), whereas a larger grant is less likely to be exercised in large parts (hence, the negative coefficients if the threshold is $25 \%$ or $50 \%$ ).

Our results may be influenced by the fact that the exercise decisions of CEOs combine two groups of decisions: option exercises where managers keep the shares, and exercises where they sell the shares immediately after they exercise them. In particular, utility theory suggests that the main benefit from option exercises are the benefits from diversification, and managers will obtain these benefits only if they sell the shares. The fact that we also include exercises where the shares are not sold may then bias our results against utility theory. We repeat our analysis therefore for the subsample of all those option exercises where shares are sold. If an option holder files at least one option exercise with a corresponding stock sale in the same SEC insider filing, we consider all transactions in this filing as an exercise event, no matter to which option package the shares initially belonged. $83 \%$ of all exercise transactions have stock sales in the same SEC filing. 
[Insert Tables 12 about here.]

Table 12 shows that the results are very similar to the previous analysis. In particular, the coefficients that support our conclusions regarding utility theory on Correlation, Volatility, and OtherCompensation are virtually unchanged with similar significance levels. The results for FirmSecurities are somewhat weakened and only the significance of ValueThisGrant has effectively vanished with five positive and five negative significance, none of which is significant. By contrast, the coefficients on some other variables are stronger. In particular, the coefficient on $C E O$ has gained significance (t-value is -9.26 instead of -6.53 , significant in 6 cases rather than 2 before). Also, the coefficient on $C A R 2$ has become more significant now. The coefficients on cumulative abnormal returns may be affected by the fact that for option exercises the direction of the trade may have a bigger impact. Insiders can be prosecuted for stock purchases and stock sales alike. However, while they can be prosecuted for exercising their stock options (and then selling the stock) when subsequent returns are negative, they cannot be prosecuted for not exercising their options when subsequent returns are positive.

[Insert Table 13 about here.]

We conduct our analysis of past stock returns using regression-alphas. In Table 13 we use raw returns instead of alphas. The results are similar, but the significance is higher for Return 156 than for Alpha156 and the difference in significance is even larger for Return52 compared to Alpha52, so the results seem to be more consistent for raw returns. From this we conclude that managers tend to extrapolate raw returns rather than relative performance.

\section{Conclusion}

We analyze managers' decision to exercise stock options using hazard analysis. This provides us with the opportunity to explicitly take into account time-varying variables and to take into account censoring. We distinguish behavioral approaches, utility theory, asymmetric information, and institutional constraints as the main approaches to explain stock option exercise decisions. We compare the explanatory power of these theoretical approaches.

Utility theory is based on the notion that managers exercise their options early in order to diversify their portfolios. We find that this approach has very little explanatory power. Utilitybased models predict that managers exercise their options once the stock price crosses above an exercise boundary, but we find that, if anything, the opposite is the case. Also, managers 
with higher non-firm related wealth exercise their options earlier, not later, whereas managers of riskier firms exercise their options later. Finally, if their stock is more correlated with the stock market index, then managers can hedge the risk of their options better, but in fact these managers consistently exercise their options earlier rather than later, as utility theory would predict. We conclude that diversification is not a relevant motive for explaining stock option exercises.

By contrast, several behavioral hypotheses do have significant explanatory power. The executives in our sample tend to exercise their options when their stock trades above the 52-week high, and they postpone exercises when the stock trades below its 52-week low, which we interpret as evidence for reference dependence. There is strong evidence that managers expect short-term trends to revert, and weak evidence that they expect long-term trends to continue. However, the managers in our sample seem to recognize situations when stock prices are likely to be inflated by investor sentiment and exercise their options faster when investor sentiment is high.

There is consistent evidence for asymmetric information and managers seem to use some information when deciding on exercising their options. However, exercises forecast medium term stock price developments (one or two quarters) and do not seem to be related to short-term stock price developments (two weeks). We interpret this as an indication of a more cautious behavior where manages make sure their exercises cannot be classified as insider trading. The economic impact of asymmetric information is small compared to other factors.

Some institutional factors are important. Managers seem to maintain their option portfolios at some target level and exercise options when new options are granted. Also, managers avoid blackout periods and move exercises from the time before earnings announcements to the period immediately after earnings announcements. Vesting restrictions are binding and managers exercise many options immediately after they vest. Interestingly, dividend capture is not an important motive and, if anything, managers exercise more options after dividend payments than before.

We therefore conclude that behavioral and institutional factors have a first-order impact and largely drive option exercise decisions, whereas asymmetric information has a more moderate role. By contrast, utility theory has no explanatory power.

One limitation of our approach is that we cannot directly investigate the importance of liquidity shocks, for example when manager make major consumption decisions or when they leave the firm. We believe that these factors also have some impact, but we do not have data that would allow us to investigate them in a large sample. 
An open question is how the factors we analyze so far influence the valuation of employee stock options. The literature on ESO valuation has focused on the utility approach and reducedform modeling of liquidity shocks. We reject the first approach and cannot test the second. Applying the insights from this paper to ESO valuation is surely a fruitful avenue of investigation which we leave for future research. 


\section{References}

[1] Armstrong, Christopher S.; Alan D. Jagolinzer, and David F. Larcker, 2007, Timing of Employee Stock Option Exercises and the Cost of Option Grants, Working Paper, Stanford University, (June)

[2] Baker, Malcolm, and Jeffrey Wurgler, 2006, Investor Sentiment and the Cross-Section of Stock Returns, Journal of Finance 61, no. 4 (August), pp. 1645-1680

[3] Barone-Adesi, Giovanni, and Robert E. Whaley, 1987, Efficient Analytic Approximation of American Option Values, Journal of Finance 42, no. 2 (June), pp. 301-320

[4] Becker, Bo, 2006, Wealth, Risk Aversion and CEO Compensation, Journal of Finance 61, no. 1 (February), pp. 379-397

[5] Bettis, J. Carr; John M. Bizjak, and Michael L. Lemmon, 2001, Managerial ownership, incentive contracting, and the use of zero-cost collars and equity swaps by corporate insiders, Journal of Financial and Quantitative Analysis 36, pp. 345-370.

[6] - 2005, Exercise Behavior, Valuation, and the Incentive Effects of Employee Stock Options, Journal of Financial Economics 76, pp. 455-470

[7] Bettis, J. Carr; Jeffrey L. Coles, and Michael L. Lemmon, 2000, Corporate Policies Restricting Trading by Insiders, Journal of Financial Economics 57, pp. 191-220

[8] Cameron, A. Colin, and Pravin K. Trivedi, 2005, Microeconometrics: Methods and Applications, Cambridge et. al. (Cambridge University Press)

[9] Carpenter, Jennifer N., 1998, The Exercise and Valuation of Executive Stock Options, Journal of Financial Economics 48, no. 2 , pp. 127-158

[10] Carpenter, Jennifer N., and Barbara Remmers, 2001, Executive Stock Option Exercises and Inside Information, Journal of Business 74, no. 4 (October)

[11] Dahiya, Sandeep, and David Yermack, 2007, You Can't Take It With You: Sunset Provisions for Equity Compensation When Managers Retire, Resign, or Die, Working Paper, New York University, (December)

[12] Detemple, J., and S. Sundaresan, 1999, Nontraded Asset Valuation With Portfolio Constraints: a Binomial Approach, Review of Financial Studies 12, no. 4 , pp. 835-72 
[13] Dittmann, Ingolf, and Ernst. Maug, 2007, Lower Salaries and No Options? On the Optimal Structure of Executive Pay, Journal of Finance 62, no. 1 (February), pp. 303-343

[14] Hallock, Kevin F., and Craig A. Olson, 2006, The Value of Stock Options to Non-Executive Employees, NBER Working Paper, no. 11950 (January)

[15] Heath, Chip; Steven Huddart, and Mark Lang, 1999, Psychological Factors and Stock Option Exercise, Quarterly Journal of Economics 114, no. 2 (May), pp. 601-27

[16] Huddart, Steven J., 1994, Employee Stock Options, Journal of Accounting and Economics 18, pp. $207-231$

[17] Huddart, Steven J., and Mark Lang, 1996, Employee Stock Option Exercises: An Empirical Analysis, Journal of Accounting and Economics 21, pp. 5-43

[18] Jennergren, L., and B. Näslund, 1993, A Comment on "Valuation of Executive Stock Options and the FASB Proposal", Accounting Review 68, pp. 179-183

[19] Kahneman, Daniel, and Amos Tversky, 1973, On the Psychology of Prediction, Psychological Review 80, no. 4 (July), pp. 237-251

[20] Kahneman, Daniel, and Amos Tversky, 1979, Prospect Theory: An Analysis of Decision Under Risk, Econometrica 47, no. 2 (March), pp. 263-292

[21] Kiefer, Nicholas M., 1988, Economic Duration Data and Hazard Functions, Journal of Economic Literature 26, no. 2 (June), pp. 646-679

[22] Lancaster, Tony, 1990, The Econometric Analysis of Transition Data, Cambridge (Cambridge University Press)

[23] Lee, Charles M. C.; Andrei Shleifer, and Richard H. Thaler, 1991, Investor Sentiment and the Closed-End Fund Puzzle, Journal of Finance 46, no. 1 (March), pp. 75-109

[24] Lemmon, Michael L., and Evgenia Portniaguina, 2008, Consumer Confidence and Asset Prices: Some Empirical Evidence, Review of Financial Studies, forthcoming

[25] Liu, Crocker H., and David Yermack, 2007, Where Are the Shareholders' Mansions? CEOs' Home Purchases, Stock Sales, and Subsequent Company Performance, Working Paper, Arizona State University, (October) 
[26] Malmendier, Ulrike, and Geoffrey Tate, 2005, CEO Overconfidence and Corporate Investment, Journal of Finance 60, no. 6 (December), pp. 2661-2700

[27] Malmendier, Ulrike, and Geoffrey Tate, 2005, Does Overconfidence Affect Corporate Investment? CEO Overconfidence Measures Revisited, European Financial Management 11, no. 5 (November), pp. 649-659

[28] Marquardt, Carol A., 2002, The Cost of Employee Stock Options Grants: An Empirical Analysis, Journal of Accounting Research 40, no. 4 (September), pp. pp. 1191-

[29] Mazumdar, Sumon C.; Vikram K. Nanda, and Rahul Surana, 2007, Using Auctions to Price Employee Stock Options: The Case of Zions Bancorporation ESOARS, Working Paper, Arizona State University, (August)

[30] Ofek, Eli, and David Yermack, 2000, Taking Stock: Equity-Based Compensation and the Evolution of Managerial Ownership, Journal of Finance 55, no. 3 , pp. 1367-1384

[31] Qiu, Lily Xiaoli, and Ivo Welch, 2006, Investor Sentiment Measures, Working Paper, Brown University, (July)

[32] Royston, Patrick, 2006, Explained variation for survival models, Stata Journal 6, no. 1, pp. $83-96$

[33] Sautner, Zacharias, and Martin Weber, 2006, How Do Managers Behave in Stock Option Plans? Evidence From Exercise and Survey Data, Working Paper, University of Amsterdam, (July)

[34] — 2008, What Determines How Top Managers Value Their Stock Options?, Working Paper, University of Amsterdam, (July)

[35] Tversky, Amos, and Daniel Kahneman, 1971, Belief in the Law of Small Numbers, Psychological Bulletin 76, no. 2, pp. 105-110 


\section{Tables}

Table 1: Sample design from raw IFDF data to our final sample. We report the number of option packages, the number of exercises, the number of persons, and the number of firms for derivatives with non-missing entries for the strike price, vesting date, and expiration date in IFDF. We show losses of observations after matching the IFDF data with ExecuComp and Datastream. We drop options that are never in the money or that never become vested. We only consider exercises where at least $25 \%$ of the initially granted option package are involved in a transaction.

\begin{tabular}{lrrrr}
\hline & $\begin{array}{r}\text { Option } \\
\text { packages }\end{array}$ & Exercises & Persons & Firms \\
\hline IFDF data & $1,534,713$ & 204,304 & 124,766 & 11,828 \\
Observations lost because of: & & & & \\
Missing compensation data & $1,264,340$ & 143,001 & 107,214 & 9,381 \\
No stock price information & 37,343 & 7,215 & 882 & 74 \\
Options never exerciseable & 45,334 & 21,793 & 987 & 47 \\
Final sample & 187,696 & 32,295 & 15,683 & 2,326 \\
\hline
\end{tabular}

Table 2: Option characteristics. Information is for the vesting date. The BAW-value is the BaroneAdesi and Whaley (1987) value for American options. Volatility is the volatility of the return of the underlying stock for weekly data measured over the 52 weeks before vesting. The interest rate is the yield of a zero-coupon government bond closest to the maturity of the respective option, where we use maturities of $1,2,3,5$, and 10 years.

\begin{tabular}{lrrrrrr}
\hline & $\begin{array}{r}\text { Option } \\
\text { packages }\end{array}$ & Mean & Std. Dev & $\begin{array}{r}\text { First } \\
\text { Quartile }\end{array}$ & Median & $\begin{array}{r}\text { Third } \\
\text { Quartile }\end{array}$ \\
\hline BAW-value (\$ million) & 185,695 & 0.87 & 22.42 & 0.02 & 0.09 & 0.35 \\
Time to maturity (years) & 187,696 & 7.52 & 2.02 & 6.73 & 7.98 & 8.98 \\
Stock price/Strike price & 187,183 & 7.48 & 537.14 & 1.01 & 1.29 & 1.85 \\
Volatility & 185,700 & 0.44 & 0.24 & 0.28 & 0.39 & 0.54 \\
Dividend yield (\%) & 187,696 & 0.79 & 1.48 & 0.00 & 0.00 & 1.12 \\
Interest rate (\%) & 187,696 & 4.54 & 0.96 & 4.01 & 4.38 & 5.07 \\
\hline
\end{tabular}

Table 3: Descriptive statistics on exercise strategies. The table reports the importance of fractional exercise in out sample. It has information on exercise choice if the holder owns at least two option packages. We report if an option package with a dividend paying underlying is exercised above the BAW exercise boundary.

\begin{tabular}{lrrr}
\hline & $\begin{array}{r}\text { Option } \\
\text { packages }\end{array}$ & Mean & Std. Dev \\
\hline Early exercises per package (if exercised) & 29,442 & 1.10 & 0.32 \\
Fraction exercised early (if exercised) & 29,442 & 0.83 & 0.26 \\
Exercise option with max. BAW-value/Inner value & 30,733 & 0.36 & 0.48 \\
Exercise option with min. BAW-value/Inner value & 30,733 & 0.15 & 0.35 \\
Option exercised above BAW-threshold & 13,785 & 0.18 & 0.38 \\
\hline
\end{tabular}


Table 4: Reasons for right censoring. We define options where the database does not record exercises before maturity as right censored. We exclude the the week of expiry in the analysis. This table reports for each possible reason for right censoring the total number of option packages, the percentage of the total, and the percentage of packages that are in the money (ITM) or out of the money (OTM) at the right censoring date. A fraction of one and the same option can be censored while others are non-censored. In such cases we take that censoring reason as representative for the whole package that applies to its largest fraction.

\begin{tabular}{lrr}
\hline Censoring reason & Number & \% of total \\
\hline Expired in the money & 12,339 & 6.6 \\
Expired out of the money & 2,109 & 1.1 \\
Holder left firm & 13,502 & 7.2 \\
Alive in Jan. 2007 & 134,936 & 71.9 \\
No censoring & 24,810 & 13.2 \\
\hline Total & 187,696 & 100.0 \\
\hline
\end{tabular}

Table 5: Key financial firm statistics. For each firm we average the observations from 1996 to 2006 for all years where at least one option package exists and where we have data. All accounting numbers are in million dollars. Panel A includes all firms in our final sample, Panel B includes all firms on IFDF. We can match only 2,114 of the 2,326 firms in our sample and only 9,451 of the 11,828 firms on IFDF to WorldScope.

Panel A: Firms in our final sample

\begin{tabular}{lrrrrrr}
\hline & Firms & Mean & $\begin{array}{r}\text { Std. } \\
\text { Dev }\end{array}$ & $\begin{array}{r}\text { First } \\
\text { Quartile }\end{array}$ & Median & $\begin{array}{r}\text { Third } \\
\text { Quartile }\end{array}$ \\
\hline Market capitalization & 2,105 & 5,899 & 19,165 & 533 & 1,268 & 3,971 \\
Book value of assets & 2,107 & 10,078 & 49,750 & 423 & 1,263 & 4,573 \\
Sales & 2,111 & 3,804 & 10,552 & 355 & 964 & 2,815 \\
Net Income & 2,113 & 238 & 961 & 8 & 43 & 156 \\
Employees & 2,099 & 14,348 & 41,896 & 1,271 & 4,025 & 11,726 \\
Employees with option grants & 2,114 & 5 & 3 & 3 & 5 & 7 \\
Market to book ratio & 2,100 & 5.1 & 35 & 1.7 & 2.6 & 4.0 \\
Net income/Sales & 2,110 & -0.1 & 2 & 0.0 & 0.0 & 0.1 \\
P/E ratio & 2,104 & 23.3 & 108 & 9.1 & 17.6 & 26.2 \\
\hline
\end{tabular}

Panel B: IFDF Firms

\begin{tabular}{lrrrrrr}
\hline & Firms & Mean & $\begin{array}{r}\text { Std. } \\
\text { Dev }\end{array}$ & $\begin{array}{r}\text { First } \\
\text { Quartile }\end{array}$ & Median & $\begin{array}{r}\text { Third } \\
\text { Quartile }\end{array}$ \\
\hline Market capitalization & 9,349 & 1,595 & 9,472 & 33 & 137 & 596 \\
Book value of assets & 9,409 & 2,743 & 24,324 & 35 & 157 & 706 \\
Sales & 9,421 & 1,074 & 5,836 & 19 & 80 & 386 \\
Net Income & 9,423 & 53 & 478 & -6 & 1 & 15 \\
Employees & 9,308 & 4,266 & 21,725 & 101 & 375 & 1,909 \\
Employees with option grants & 9,451 & 9 & 7 & 4 & 8 & 12 \\
\hline
\end{tabular}




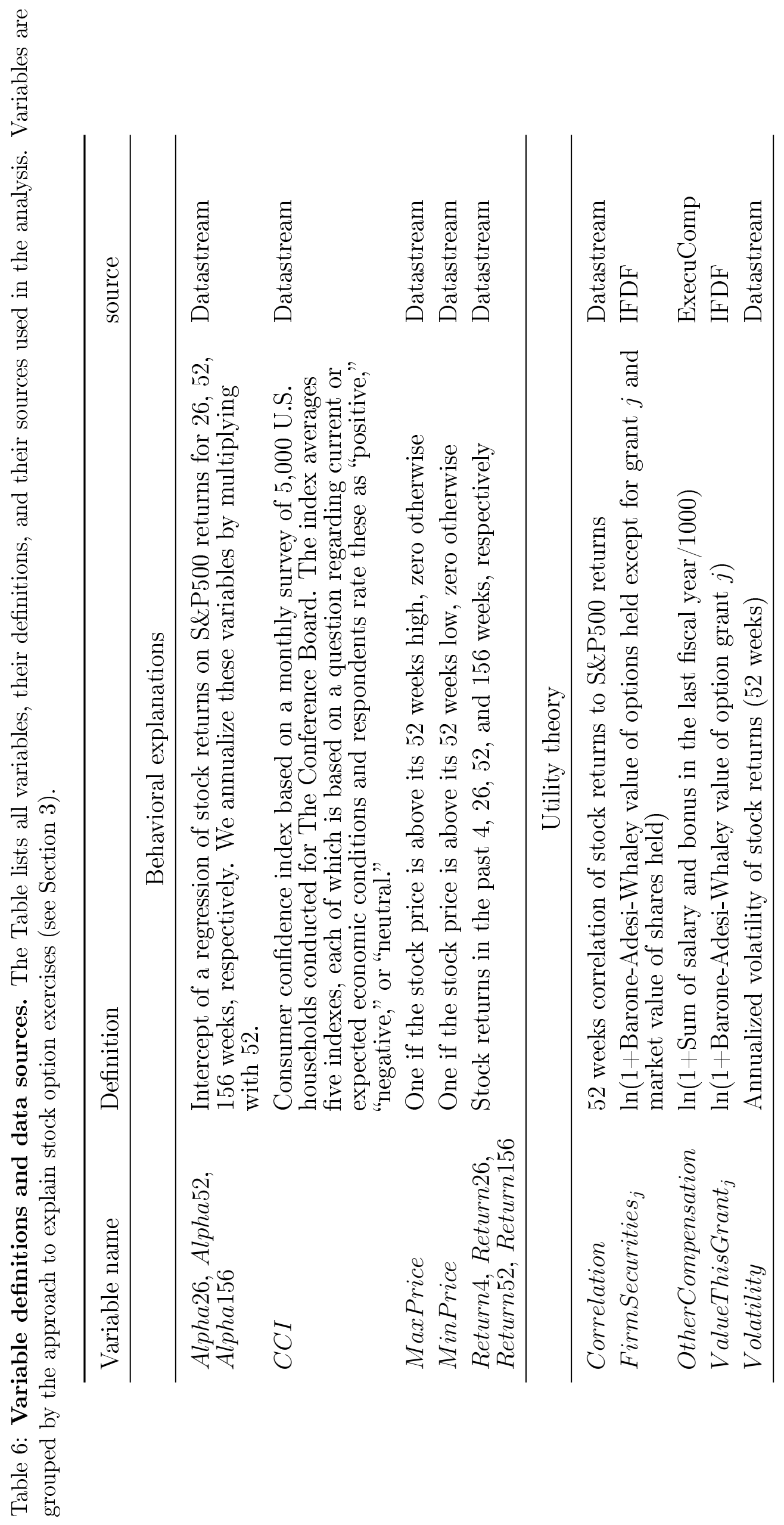




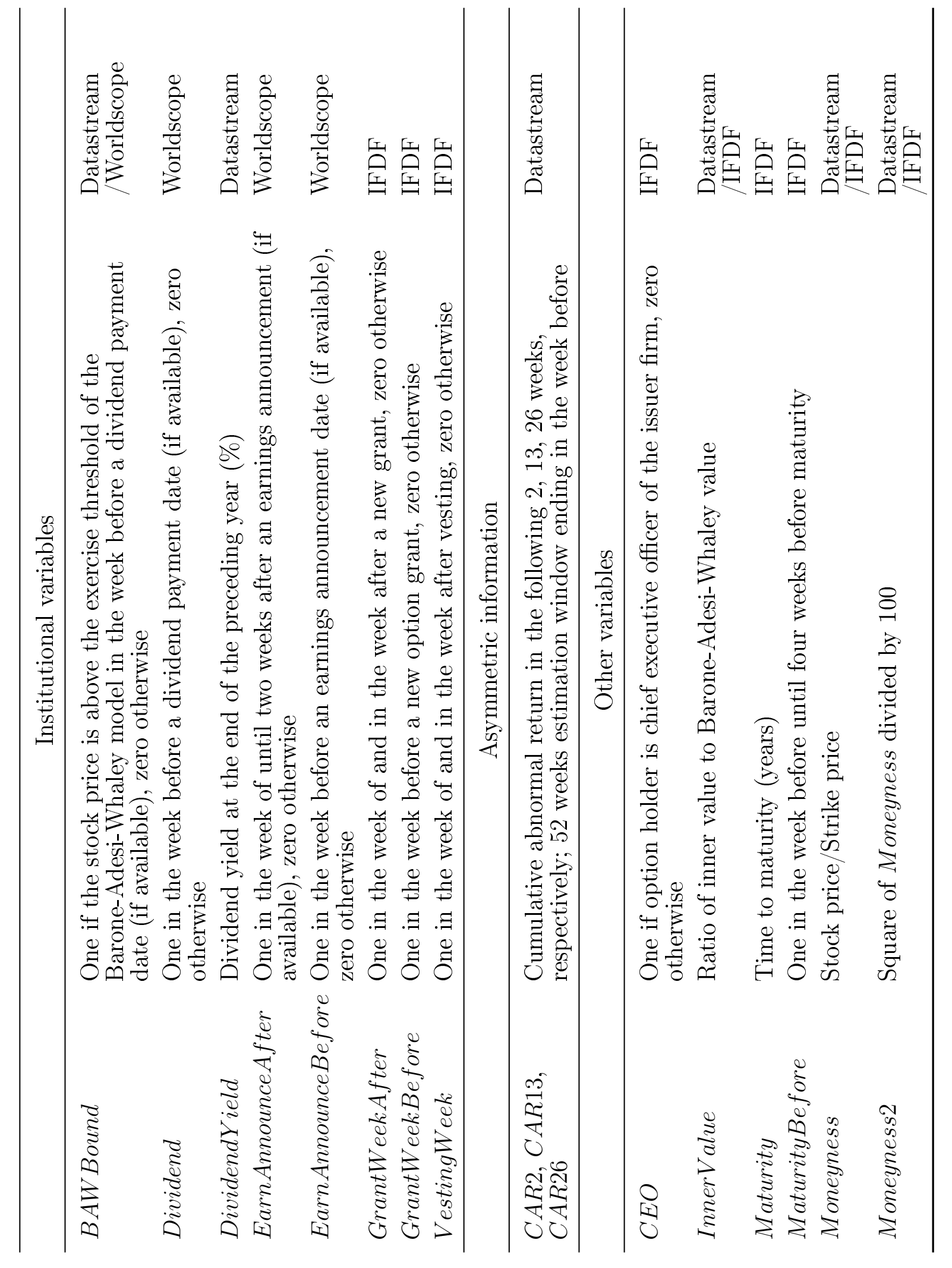


Table 7: Descriptive statistics on option packages. All variable definitions are contained in Table 6. The table contains information on all variables in the baseline specification. We first calculate means for each option package including all weekly observations where the option package is exerciseable. The statistics in the table are calculated from these means.

\begin{tabular}{|c|c|c|c|c|c|c|}
\hline & $\begin{array}{r}\text { Option } \\
\text { packages }\end{array}$ & Mean & Std. Dev & $\begin{array}{r}\text { First } \\
\text { Quartile }\end{array}$ & Median & $\begin{array}{r}\text { Third } \\
\text { Quartile }\end{array}$ \\
\hline \multicolumn{7}{|l|}{ Behavioral } \\
\hline Alpha26 & 187,696 & .18 & 1.9 & .012 & .14 & .29 \\
\hline Alpha52 & 187,696 & .17 & 1.2 & .027 & .14 & .28 \\
\hline Alpha 156 & 187,696 & .17 & .45 & .05 & .15 & .25 \\
\hline$C C I$ & 187,696 & 104 & 11 & 99 & 102 & 106 \\
\hline MaxPrice & 187,696 & .16 & .18 & .055 & .13 & .2 \\
\hline MinPrice & 187,696 & .023 & .057 & 0 & 0 & .028 \\
\hline \multicolumn{7}{|l|}{ Utility } \\
\hline Correlation & 187,696 & .42 & .15 & .33 & .43 & .52 \\
\hline FirmSecurities $_{j}$ & 187,696 & 16 & 1.8 & 15 & 16 & 17 \\
\hline Moneyness & 187,696 & 8.4 & 411 & 1.2 & 1.6 & 2.3 \\
\hline Moneyness 2 & 187,696 & $2.2 \mathrm{e}+03$ & $2.6 \mathrm{e}+05$ & .015 & .025 & .055 \\
\hline OtherCompensation & 187,696 & 6.2 & 1.4 & 5.8 & 6.3 & 6.9 \\
\hline ValueThisGrant & 187,696 & 12 & 2.2 & 10 & 12 & 13 \\
\hline Volatility & 187,696 & .38 & 1.3 & .25 & .34 & .45 \\
\hline \multicolumn{7}{|l|}{ Institutional } \\
\hline Dividend & 187,696 & $4.4 \mathrm{e}-03$ & .02 & 0 & 0 & 0 \\
\hline$B A W$ Bound & 187,696 & $2.3 \mathrm{e}-05$ & $8.4 \mathrm{e}-04$ & 0 & 0 & 0 \\
\hline DividendYield & 187,696 & .76 & 1.3 & 0 & 0 & 1.1 \\
\hline EarnAnnounceAfter & 187,696 & .018 & .05 & 0 & 0 & 0 \\
\hline EarnAnnounceBefore & 187,696 & $5.8 \mathrm{e}-03$ & .018 & 0 & 0 & 0 \\
\hline GrantWeekAfter & 187,696 & .04 & .096 & 0 & .02 & .045 \\
\hline GrantWeekBefore & 187,696 & .016 & .037 & 0 & $6.6 \mathrm{e}-03$ & .02 \\
\hline VestingWeek & 187,696 & .065 & .17 & 0 & .016 & .043 \\
\hline \multicolumn{7}{|c|}{ Asymmetric Information } \\
\hline$C A R 2$ & 187,696 & -.01 & .075 & -.013 & $-4.4 \mathrm{e}-03$ & $-3.5 \mathrm{e}-04$ \\
\hline$C A R 13$ & 187,696 & -.06 & .35 & -.082 & -.029 & $-3.4 \mathrm{e}-03$ \\
\hline$C A R 26$ & 187,696 & -.11 & .63 & -.16 & -.061 & $-7.9 \mathrm{e}-03$ \\
\hline \multicolumn{7}{|l|}{ Other } \\
\hline$C E O$ & 187,696 & .15 & .36 & 0 & 0 & 0 \\
\hline InnerValue & 187,696 & .6 & .28 & .38 & .64 & .83 \\
\hline Maturity & 187,696 & 5.6 & 2.1 & 4.5 & 6 & 7 \\
\hline Maturity $4 W$ eeksBefore & 187,696 & $3.7 \mathrm{e}-03$ & .043 & 0 & 0 & 0 \\
\hline
\end{tabular}


Table 8: Hazard rates $\left(h r_{i}=\exp \left\{\beta_{i}\right\}-1\right.$, where $\beta_{i}$ is the respective coefficient) for hazard regressions on ten equally sized random samples (option packages not split up). The dependent variable is Exercise, which equals one if the fraction exercised equals at least $25 \%$ of the option package initially granted. In addition to the independent variables shown we included dummy variables for calendar years, vesting years, and seasonal effects.

\begin{tabular}{|c|c|c|c|c|c|}
\hline & 1 & 2 & 3 & 4 & 5 \\
\hline \multicolumn{6}{|l|}{ Behavioral } \\
\hline Alpha26 & $1.43 * * *$ & $0.19 * * *$ & $0.20 * * *$ & $0.20 * * *$ & $0.20 * * *$ \\
\hline Alpha52 & 0.26 & 0.06 & 0.06 & 0.04 & 0.04 \\
\hline Alpha156 & -0.07 & $-0.06 *$ & -0.06 & -0.00 & $-0.07 * *$ \\
\hline$C C I$ & $0.15 * * *$ & $0.09 *$ & 0.07 & $0.15 * * *$ & $0.12 * *$ \\
\hline MaxPrice & $0.67 * * *$ & $0.67 * * *$ & $0.67 * * *$ & $0.70 * * *$ & $0.67 * * *$ \\
\hline MinPrice & $-0.35 *$ & $-0.40 * *$ & $-0.39 * *$ & -0.06 & $-0.47 * *$ \\
\hline \multicolumn{6}{|l|}{ Utility } \\
\hline Correlation & $0.10 * * *$ & $0.11 * * *$ & $0.11 * * *$ & $0.12 * * *$ & $0.11^{* * *}$ \\
\hline FirmSecurities $_{j}$ & $-0.06 *$ & $-0.07 * *$ & -0.04 & $-0.07 * *$ & -0.05 \\
\hline Moneyness & -0.05 & $-0.03 * *$ & -0.01 & -0.05 & -0.08 \\
\hline Moneyness 2 & 0.02 & $0.03 * * *$ & 0.01 & -0.12 & $0.04 * *$ \\
\hline OtherCompensation & 0.03 & $0.05 * *$ & $0.05 * *$ & 0.03 & $0.07 * * *$ \\
\hline ValueThisGrant & -0.03 & -0.02 & $-0.08 * *$ & -0.03 & $-0.07 * *$ \\
\hline Volatility & $-0.77 * * *$ & $-0.08 * *$ & $-0.09 * * *$ & $-0.09 * * *$ & $-0.07 * *$ \\
\hline \multicolumn{6}{|l|}{ Institutional } \\
\hline Dividend & $-0.50 * *$ & $-0.48 *$ & -0.16 & -0.05 & -0.00 \\
\hline$B A W$ Bound & $-1.00 * * *$ & $-1.00 * * *$ & 2.15 & $-1.00 * * *$ & 1.42 \\
\hline DividendYield & -0.01 & 0.02 & 0.00 & 0.04 & 0.01 \\
\hline EarnAnnounceAfter & $0.86 * * *$ & $1.05 * * *$ & $0.91 * * *$ & $0.78 * * *$ & $0.86 * * *$ \\
\hline EarnAnnounceBefore & -0.49 & $-0.70 * *$ & $-0.72 * *$ & $-0.76 * *$ & $-0.68 * *$ \\
\hline GrantWeekAfter & $3.62 * * *$ & $4.52 * * *$ & $3.99 * * *$ & $4.43 * * *$ & $3.90 * * *$ \\
\hline GrantWeekBefore & -0.20 & 0.03 & -0.14 & 0.05 & -0.18 \\
\hline VestingWeek & $9.04^{* * *}$ & $8.99 * * *$ & $8.91 * * *$ & $9.02 * * *$ & $11.32 * * *$ \\
\hline \multicolumn{6}{|l|}{ Asymmetric Information } \\
\hline$C A R 2$ & -0.06 & -0.01 & -0.01 & 0.02 & $-0.04 * *$ \\
\hline$C A R 13$ & $-0.23 * * *$ & $-0.06 * *$ & -0.04 & $-0.09 * * *$ & -0.05 \\
\hline$C A R 26$ & 0.02 & -0.04 & $-0.07 * *$ & -0.01 & $-0.08 * *$ \\
\hline \multicolumn{6}{|l|}{ Other } \\
\hline$C E O$ & -0.01 & -0.02 & $-0.11 *$ & $-0.13 * *$ & -0.08 \\
\hline InnerValue & $0.88 * * *$ & $0.99 * * *$ & $0.95 * * *$ & $0.89 * * *$ & $1.01 * * *$ \\
\hline Maturity & $-0.28 * * *$ & $-0.26 * * *$ & $-0.23 * * *$ & $-0.25 * * *$ & $-0.25 * * *$ \\
\hline Maturity 4 WeeksBefore & $3.58 * * *$ & $5.17 * * *$ & $5.22 * * *$ & $4.34 * * *$ & $4.09 * * *$ \\
\hline Constant & $-1.00 * * *$ & $-1.00 * * *$ & $-1.00 * * *$ & $-1.00 * * *$ & $-1.00 * * *$ \\
\hline $\ln (p)$ & $0.10^{* * *}$ & $0.11 * * *$ & $0.11 * * *$ & $0.12 * * *$ & $0.12 * * *$ \\
\hline$R^{2}$ & 0.75 & 0.75 & 0.76 & 0.75 & 0.76 \\
\hline
\end{tabular}




\begin{tabular}{|c|c|c|c|c|c|}
\hline & 6 & 7 & 8 & 9 & 10 \\
\hline \multicolumn{6}{|l|}{ Behavioral } \\
\hline Alpha26 & $0.25 * * *$ & $0.21 * * *$ & $0.24 * * *$ & $0.21 * * *$ & $0.29 * * *$ \\
\hline Alpha52 & -0.04 & 0.05 & 0.01 & 0.04 & -0.04 \\
\hline Alpha156 & 0.04 & -0.02 & -0.05 & -0.02 & $-0.05 *$ \\
\hline$C C I$ & $0.16 * * *$ & $0.13 * *$ & $0.12 * *$ & $0.18 * * *$ & $0.10 *$ \\
\hline MaxPrice & $0.72 * * *$ & $0.45 * * *$ & $0.74 * * *$ & $0.64 * * *$ & $0.54 * * *$ \\
\hline MinPrice & -0.16 & $-0.36 *$ & -0.27 & -0.18 & $-0.45 * *$ \\
\hline \multicolumn{6}{|l|}{ Utility } \\
\hline Correlation & $0.09 * * *$ & $0.09 * * *$ & $0.13 * * *$ & $0.09 * * *$ & $0.13^{* * *}$ \\
\hline FirmSecurities $_{j}$ & -0.04 & $-0.05 *$ & -0.04 & $-0.06 * *$ & $-0.07 * *$ \\
\hline Moneyness & -0.02 & -0.60 & -0.05 & $-0.14 * * *$ & 0.08 \\
\hline Moneyness 2 & 0.01 & 0.70 & 0.04 & $0.10 * * *$ & -0.33 \\
\hline OtherCompensation & $0.05 * *$ & $0.05 * *$ & 0.03 & $0.10 * * *$ & $0.08 * * *$ \\
\hline ValueThisGrant & -0.05 & -0.04 & -0.05 & -0.04 & $-0.07 * *$ \\
\hline Volatility & $-0.09 * * *$ & $-0.12 * * *$ & $-0.08 * *$ & $-0.13 * * *$ & $-0.06 * *$ \\
\hline \multicolumn{6}{|l|}{ Institutional } \\
\hline Dividend & 0.10 & -0.31 & $-0.40 *$ & -0.30 & 0.05 \\
\hline$B A W$ Bound & $-1.00 * * *$ & $5.69 *$ & $6.27 * * *$ & $-1.00 * * *$ & 1.77 \\
\hline DividendYield & $0.06 *$ & 0.01 & 0.01 & -0.04 & 0.02 \\
\hline EarnAnnounceAfter & $1.07 * * *$ & $0.74 * * *$ & $0.87 * * *$ & $0.76 * * *$ & $0.34 * *$ \\
\hline EarnAnnounceBefore & -0.41 & $-0.74 * * *$ & $-0.60 *$ & $-0.63 * *$ & $-0.52 *$ \\
\hline GrantWeekAfter & $4.05 * * *$ & $4.03^{* * *}$ & $4.26 * * *$ & $4.02 * * *$ & $4.23 * * *$ \\
\hline GrantWeekBefore & -0.17 & 0.06 & 0.07 & -0.16 & -0.22 \\
\hline VestingWeek & $9.64^{* * *}$ & $9.74 * * *$ & $13.01 * * *$ & $8.55^{* * *}$ & $10.03^{* * *}$ \\
\hline \multicolumn{6}{|l|}{ Asymmetric Information } \\
\hline$C A R 2$ & -0.01 & -0.00 & 0.00 & -0.02 & -0.00 \\
\hline$C A R 13$ & -0.05 & -0.04 & -0.05 & -0.04 & 0.01 \\
\hline$C A R 26$ & $-0.08 * *$ & $-0.07 *$ & $-0.08 * *$ & -0.02 & $-0.13 * * *$ \\
\hline \multicolumn{6}{|l|}{ Other } \\
\hline$C E O$ & $-0.09 *$ & -0.06 & -0.05 & -0.08 & $-0.13 * *$ \\
\hline InnerValue & $0.89 * * *$ & $0.91 * * *$ & $0.96 * * *$ & $1.01 * * *$ & $0.97 * * *$ \\
\hline Maturity & $-0.26 * * *$ & $-0.26 * * *$ & $-0.27 * * *$ & $-0.23 * * *$ & $-0.26 * * *$ \\
\hline Maturity 4 WeeksBefore & $5.15 * * *$ & $4.82 * * *$ & $3.15^{* * *}$ & $5.20 * * *$ & $3.19^{* * *}$ \\
\hline Constant & $-1.00 * * *$ & $-1.00 * * *$ & $-1.00 * * *$ & $-1.00 * * *$ & $-1.00 * * *$ \\
\hline $\ln (p)$ & $0.11 * * *$ & $0.13^{* * *}$ & $0.17 * * *$ & $0.11^{* * *}$ & $0.12 * * *$ \\
\hline$R^{2}$ & 0.76 & 0.75 & 0.77 & 0.76 & 0.76 \\
\hline
\end{tabular}


Table 9: Summary for hazard regressions. Exercise $=\mathbf{1}$ if fraction exercised is at least $\mathbf{2 5 \%}$. This table summarizes the results of Table 8 . We report the mean hazard rate $\left(h r_{i}=\exp \left\{\beta_{i}\right\}-1,\right)$ across all ten subsamples, the coefficient of variation of the hazard rate $\left(\frac{s d\left(h r_{i}\right)}{\operatorname{mean}\left(h r_{i}\right)}\right)$, the aggregated $\mathrm{t}$-value, the number of positive/negative coefficients, and the number of positive/negative coefficients that are significant at the $5 \%$ level.

\begin{tabular}{|c|c|c|c|c|c|c|c|}
\hline & $\begin{array}{r}\text { mean } \\
h r\end{array}$ & $h r$ var. & aggr. t & $\begin{array}{l}\text { pos. } \\
\text { coeffs }\end{array}$ & $\begin{array}{l}\text { neg. } \\
\text { coeffs }\end{array}$ & $\begin{array}{l}\text { pos. } \\
\text { sig. }\end{array}$ & neg. sig \\
\hline \multicolumn{8}{|l|}{ Behavioral } \\
\hline Alpha26 & 0.34 & 0.58 & 26.64 & 10 & 0 & 10 & 0 \\
\hline Alpha52 & 0.05 & 0.09 & 3.95 & 8 & 2 & 0 & 0 \\
\hline Alpha156 & -0.04 & 0.03 & -6.45 & 1 & 9 & 0 & 1 \\
\hline$C C I$ & 0.13 & 0.04 & 14.80 & 10 & 0 & 7 & 0 \\
\hline MaxPrice & 0.65 & 0.25 & 44.05 & 10 & 0 & 10 & 0 \\
\hline MinPrice & -0.31 & 0.10 & -2.45 & 0 & 10 & 0 & 4 \\
\hline \multicolumn{8}{|l|}{ Utility } \\
\hline Correlation & 0.11 & 0.02 & 40.38 & 10 & 0 & 10 & 0 \\
\hline FirmSecurities $_{j}$ & -0.05 & 0.01 & -17.30 & 0 & 10 & 0 & 4 \\
\hline Moneyness & -0.10 & 0.17 & -0.31 & 1 & 9 & 0 & 2 \\
\hline Moneyness2 & 0.05 & 0.27 & 0.07 & 8 & 2 & 3 & 0 \\
\hline OtherCompensation & 0.05 & 0.02 & 31.81 & 10 & 0 & 7 & 0 \\
\hline ValueThisGrant & -0.05 & 0.02 & -12.78 & 0 & 10 & 0 & 3 \\
\hline Volatility & -0.16 & 0.19 & -21.72 & 0 & 10 & 0 & 10 \\
\hline \multicolumn{8}{|l|}{ Institutional } \\
\hline Dividend & -0.21 & 0.18 & -0.92 & 2 & 8 & 0 & 1 \\
\hline$B A W$ Bound & 1.23 & 12.27 & -2.92 & 5 & 5 & 1 & 5 \\
\hline DividendYield & 0.01 & 0.03 & 4.44 & 8 & 2 & 0 & 0 \\
\hline EarnAnnounceAfter & 0.82 & 1.15 & 9.32 & 10 & 0 & 10 & 0 \\
\hline EarnAnnounceBe fore & -0.63 & 0.07 & -1.18 & 0 & 10 & 0 & 6 \\
\hline GrantWeekAfter & 4.10 & 0.08 & 33.25 & 10 & 0 & 10 & 0 \\
\hline GrantWeekBefore & -0.09 & 0.11 & -1.00 & 4 & 6 & 0 & 0 \\
\hline VestingWeek & 9.83 & 0.16 & 26.30 & 10 & 0 & 10 & 0 \\
\hline \multicolumn{8}{|l|}{ Asymmetric Information } \\
\hline$C A R 2$ & -0.01 & 0.02 & -7.85 & 2 & 8 & 0 & 1 \\
\hline$C A R 13$ & -0.07 & 0.06 & -12.13 & 1 & 9 & 0 & 3 \\
\hline$C A R 26$ & -0.06 & 0.04 & -8.46 & 1 & 9 & 0 & 5 \\
\hline \multicolumn{8}{|l|}{ Other } \\
\hline$C E O$ & -0.08 & 0.04 & -6.53 & 0 & 10 & 0 & 2 \\
\hline InnerValue & 0.95 & 0.95 & 126.60 & 10 & 0 & 10 & 0 \\
\hline Maturity & -0.26 & 0.01 & -83.18 & 0 & 10 & 0 & 10 \\
\hline Maturity 4 WeeksBefore & 4.39 & 0.25 & 21.53 & 10 & 0 & 10 & 0 \\
\hline Constant & -1.00 & 0.00 & -36.94 & 0 & 10 & 0 & 10 \\
\hline $\ln (p)$ & 0.12 & 0.02 & 46.67 & 10 & 0 & 10 & 0 \\
\hline
\end{tabular}


Table 10: Summary for hazard regressions. Exercise $=\mathbf{1}$ if fraction exercised is at least $\mathbf{1 0 \%}$. We report the mean hazard rate $\left(h r_{i}=\exp \left\{\beta_{i}\right\}-1,\right)$, the coefficient of variation of the hazard rate $\left(\frac{s d\left(h r_{i}\right)}{\text { mean }\left(h r_{i}\right)}\right)$, the aggregated t-value, the number of positive/negative coefficients, and the number of positive/negative coefficients that are significant to the $5 \%$ level.

\begin{tabular}{|c|c|c|c|c|c|c|c|}
\hline & $\begin{array}{r}\text { mean } \\
h r\end{array}$ & $h r$ var. & aggr. $t$ & $\begin{array}{l}\text { pos. } \\
\text { coeffs }\end{array}$ & $\begin{array}{l}\text { neg. } \\
\text { coeffs }\end{array}$ & $\begin{array}{l}\text { pos. } \\
\text { sig. }\end{array}$ & neg. sig \\
\hline \multicolumn{8}{|l|}{ Behavioral } \\
\hline Alpha26 & 0.30 & 0.44 & 27.53 & 10 & 0 & 10 & 0 \\
\hline Alpha52 & 0.05 & 0.08 & 4.60 & 8 & 2 & 0 & 0 \\
\hline Alpha156 & -0.02 & 0.03 & -4.76 & 2 & 8 & 0 & 1 \\
\hline$C C I$ & 0.10 & 0.04 & 13.56 & 10 & 0 & 7 & 0 \\
\hline MaxPrice & 0.63 & 0.19 & 50.09 & 10 & 0 & 10 & 0 \\
\hline MinPrice & -0.33 & 0.11 & -2.99 & 0 & 10 & 0 & 7 \\
\hline \multicolumn{8}{|l|}{ Utility } \\
\hline Correlation & 0.10 & 0.02 & 39.96 & 10 & 0 & 10 & 0 \\
\hline FirmSecurities $_{j}$ & -0.07 & 0.01 & -27.86 & 0 & 10 & 0 & 10 \\
\hline Moneyness & -0.09 & 0.19 & -0.32 & 2 & 8 & 0 & 2 \\
\hline Moneyness 2 & 0.07 & 0.32 & 0.21 & 8 & 2 & 3 & 0 \\
\hline OtherCompensation & 0.05 & 0.02 & 29.18 & 10 & 0 & 5 & 0 \\
\hline ValueThisGrant & 0.05 & 0.02 & 13.00 & 10 & 0 & 2 & 0 \\
\hline Volatility & -0.14 & 0.19 & -22.01 & 0 & 10 & 0 & 8 \\
\hline \multicolumn{8}{|l|}{ Institutional } \\
\hline Dividend & -0.19 & 0.21 & -1.05 & 3 & 7 & 0 & 1 \\
\hline$B A W$ Bound & 1.17 & 13.30 & -1.84 & 6 & 4 & 1 & 4 \\
\hline DividendYield & -0.00 & 0.02 & -0.19 & 5 & 5 & 0 & 0 \\
\hline EarnAnnounceAfter & 0.86 & 1.26 & 11.38 & 10 & 0 & 10 & 0 \\
\hline EarnAnnounceBefore & -0.64 & 0.05 & -1.49 & 0 & 10 & 0 & 8 \\
\hline GrantWeekAfter & 3.77 & 0.08 & 33.16 & 10 & 0 & 10 & 0 \\
\hline GrantWeekBefore & -0.09 & 0.10 & -1.19 & 3 & 7 & 0 & 0 \\
\hline VestingWeek & 9.93 & 0.14 & 28.47 & 10 & 0 & 10 & 0 \\
\hline \multicolumn{8}{|l|}{ Asymmetric Information } \\
\hline$C A R 2$ & -0.01 & 0.02 & -7.71 & 1 & 9 & 0 & 1 \\
\hline$C A R 13$ & -0.06 & 0.06 & -13.75 & 1 & 9 & 0 & 3 \\
\hline$C A R 26$ & -0.06 & 0.04 & -9.20 & 1 & 9 & 0 & 3 \\
\hline \multicolumn{8}{|l|}{ Other } \\
\hline$C E O$ & -0.06 & 0.05 & -4.88 & 1 & 9 & 0 & 2 \\
\hline InnerValue & 0.96 & 1.27 & 138.96 & 10 & 0 & 10 & 0 \\
\hline Maturity & -0.23 & 0.01 & -68.48 & 0 & 10 & 0 & 10 \\
\hline Maturity 4 WeeksBefore & 4.35 & 0.26 & 22.83 & 10 & 0 & 10 & 0 \\
\hline Constant & -1.00 & 0.00 & -37.44 & 0 & 10 & 0 & 10 \\
\hline $\ln (p)$ & 0.13 & 0.02 & 51.90 & 10 & 0 & 10 & 0 \\
\hline
\end{tabular}


Table 11: Summary for hazard regressions. Exercise $=\mathbf{1}$ if fraction exercised is at least $\mathbf{5 0 \%}$. We report the mean hazard rate $\left(h r_{i}=\exp \left\{\beta_{i}\right\}-1,\right)$, the coefficient of variation of the hazard rate $\left(\frac{s d\left(h r_{i}\right)}{\operatorname{mean}\left(h r_{i}\right)}\right)$, the aggregated t-value, the number of positive/negative coefficients, and the number of positive/negative coefficients that are significant to the $5 \%$ level.

\begin{tabular}{|c|c|c|c|c|c|c|c|}
\hline & $\begin{array}{r}\text { mean } \\
h r\end{array}$ & $h r$ var. & aggr. t & $\begin{array}{l}\text { pos. } \\
\text { coeffs }\end{array}$ & $\begin{array}{l}\text { neg. } \\
\text { coeffs }\end{array}$ & $\begin{array}{l}\text { pos. } \\
\text { sig. }\end{array}$ & neg. sig \\
\hline \multicolumn{8}{|l|}{ Behavioral } \\
\hline Alpha26 & 0.37 & 0.78 & 21.59 & 10 & 0 & 10 & 0 \\
\hline Alpha52 & 0.06 & 0.08 & 4.09 & 8 & 2 & 1 & 0 \\
\hline Alpha156 & -0.05 & 0.04 & -6.81 & 1 & 9 & 0 & 2 \\
\hline$C C I$ & 0.16 & 0.04 & 14.60 & 10 & 0 & 8 & 0 \\
\hline MaxPrice & 0.64 & 0.26 & 34.77 & 10 & 0 & 10 & 0 \\
\hline MinPrice & -0.30 & 0.11 & -1.91 & 0 & 10 & 0 & 3 \\
\hline \multicolumn{8}{|l|}{ Utility } \\
\hline Correlation & 0.12 & 0.02 & 36.21 & 10 & 0 & 10 & 0 \\
\hline FirmSecurities $_{j}$ & -0.01 & 0.02 & -3.05 & 2 & 8 & 0 & 0 \\
\hline Moneyness & 0.04 & 0.33 & 0.01 & 5 & 5 & 1 & 2 \\
\hline Moneyness 2 & -0.14 & 0.31 & -0.53 & 4 & 6 & 3 & 1 \\
\hline OtherCompensation & 0.07 & 0.03 & 30.58 & 10 & 0 & 7 & 0 \\
\hline ValueThisGrant & -0.14 & 0.02 & -41.27 & 0 & 10 & 0 & 10 \\
\hline Volatility & -0.16 & 0.19 & -19.87 & 0 & 10 & 0 & 9 \\
\hline \multicolumn{8}{|l|}{ Institutional } \\
\hline Dividend & -0.21 & 0.22 & -0.74 & 3 & 7 & 0 & 0 \\
\hline$B A W$ Bound & 1.58 & 7.00 & -3.88 & 4 & 6 & 1 & 6 \\
\hline DividendYield & 0.02 & 0.03 & 7.92 & 8 & 2 & 1 & 0 \\
\hline EarnAnnounceAfter & 0.80 & 0.95 & 7.39 & 10 & 0 & 9 & 0 \\
\hline EarnAnnounceBefore & -0.63 & 0.09 & -0.84 & 0 & 10 & 0 & 2 \\
\hline GrantWeekAfter & 4.37 & 0.08 & 31.04 & 10 & 0 & 10 & 0 \\
\hline GrantWeekBefore & -0.06 & 0.13 & -0.63 & 4 & 6 & 0 & 0 \\
\hline VestingWeek & 10.15 & 0.16 & 23.22 & 10 & 0 & 10 & 0 \\
\hline \multicolumn{8}{|l|}{ Asymmetric Information } \\
\hline$C A R 2$ & -0.02 & 0.03 & -7.81 & 2 & 8 & 0 & 1 \\
\hline$C A R 13$ & -0.07 & 0.05 & -10.76 & 1 & 9 & 0 & 4 \\
\hline$C A R 26$ & -0.05 & 0.04 & -6.70 & 1 & 9 & 0 & 2 \\
\hline \multicolumn{8}{|l|}{ Other } \\
\hline$C E O$ & -0.07 & 0.04 & -5.20 & 1 & 9 & 0 & 0 \\
\hline InnerValue & 0.93 & 0.79 & 102.13 & 10 & 0 & 10 & 0 \\
\hline Maturity & -0.30 & 0.01 & -91.61 & 0 & 10 & 0 & 10 \\
\hline Maturity 4 WeeksBefore & 4.33 & 0.29 & 18.47 & 10 & 0 & 10 & 0 \\
\hline Constant & -1.00 & 0.00 & -32.81 & 0 & 10 & 0 & 10 \\
\hline $\ln (p)$ & 0.11 & 0.02 & 38.01 & 10 & 0 & 10 & 0 \\
\hline
\end{tabular}


Table 12: Summary for hazard regressions for subsample where stock is sold. We report the mean hazard rate $\left(h r_{i}=\exp \left\{\beta_{i}\right\}-1,\right)$, the coefficient of variation of the hazard rate $\left(\frac{s d\left(h r_{i}\right)}{\operatorname{mean}\left(h r_{i}\right)}\right)$, the aggregated t-value, the number of positive/negative coefficients, and the number of positive/negative coefficients that are significant to the $5 \%$ level.

\begin{tabular}{lrrrrrrr}
\hline & mean $h r$ & $h r$ var. & aggr. $t$ & $\begin{array}{r}\text { pos. } \\
\text { coeffs }\end{array}$ & $\begin{array}{r}\text { neg. } \\
\text { coeffs }\end{array}$ & pos. sig. & neg. sig \\
\hline CEO & & & & & & & \\
\hline Correlation & -0.13 & 0.06 & -9.26 & 0 & 10 & 0 & 6 \\
FirmSecurities $j$ & 0.12 & 0.02 & 36.45 & 10 & 0 & 10 & 0 \\
OtherCompensation & -0.04 & 0.01 & -10.86 & 0 & 10 & 0 & 0 \\
ValueThisGrant & -0.06 & 0.03 & 28.00 & 10 & 0 & 6 & 0 \\
Volatility & -0.00 & 0.03 & -1.06 & 5 & 5 & 0 & 0 \\
CAR2 & -0.21 & 0.18 & -22.48 & 0 & 10 & 0 & 10 \\
\hline
\end{tabular}

Table 13: Summary for hazard regressions with raw returns. We report the mean hazard rate $\left(h r_{i}=\exp \left\{\beta_{i}\right\}-1,\right)$, the coefficient of variation of the hazard rate $\left(\frac{s d\left(h r_{i}\right)}{\operatorname{mean}\left(h r_{i}\right)}\right)$, the aggregated t-value, the number of positive/negative coefficients, and the number of positive/negative coefficients that are significant to the $5 \%$ level.

\begin{tabular}{lrrrrrrr}
\hline & mean $h r$ & $h r$ var. & aggr. $t$ & $\begin{array}{r}\text { pos. } \\
\text { coeffs }\end{array}$ & $\begin{array}{r}\text { neg. } \\
\text { coeffs }\end{array}$ & pos. sig. & neg. sig \\
\hline Behavioral & & & & & & & \\
\hline Return26 & 0.12 & 0.03 & 115.83 & 10 & 0 & 10 & 0 \\
Return52 & -0.03 & 0.02 & -25.47 & 1 & 9 & 0 & 4 \\
Return156 & -0.01 & 0.01 & -6.90 & 3 & 7 & 0 & 0 \\
CCI & 0.13 & 0.04 & 15.16 & 10 & 0 & 7 & 0 \\
MaxPrice & 0.70 & 0.35 & 45.68 & 10 & 0 & 10 & 0 \\
MinPrice & -0.42 & 0.08 & -3.45 & 0 & 10 & 0 & 7 \\
\hline
\end{tabular}

